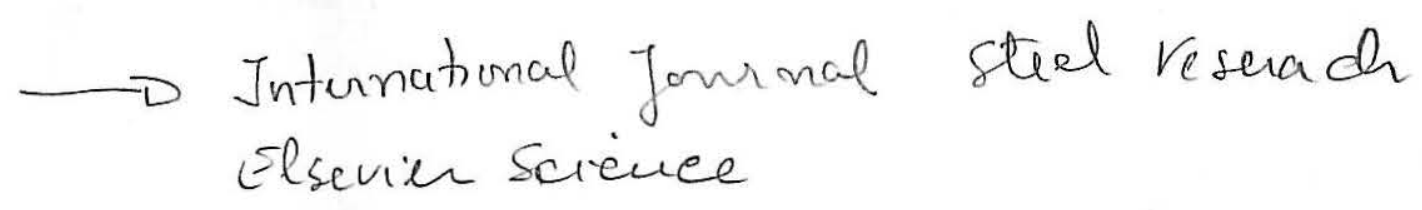

\title{
A New Proposal of a Simple Model for the Lateral-torsional Buckling of Unrestrained Steel I-Beams in case of Fire: Experimental and
}

\author{
Numerical Validation
}

\author{
Vila Real, P. M. M. ${ }^{a^{*}}$; Piloto, P. A. G. ${ }^{b}$ and Franssen, J.-M. ${ }^{c}$ \\ ${ }^{a}$ Department of Civil Engineering, University of Aveiro, \\ 3810 Aveiro, Portugal \\ Tel.: +351-234-370049; fax: +351-234-370094; e-mail: pvreal@civil.ua.pt \\ * Corresponding author \\ ${ }^{b}$ Department of Mechanical Engineering, Polytechnic of Bragança, Portugal \\ ${ }^{c}$ Department Civil Engineering, University of Liege, Belgium
}

\begin{abstract}
The behaviour of Steel I-Beams exhibiting lateral-torsional buckling at elevated temperature has been studied by means of experimental and numerical analysis. The authors in an earlier paper have presented an analytical formula for the buckling resistance moment in the fire design situation. This new proposal, different from the actual proposal of the Eurocode 3 Part 1.2 has been validated in this work by comparison with the results from a set of 120 experimental and numerical tests performed on IPE 100 beams, submitted to temperatures varying from room temperature to $600{ }^{\circ} \mathrm{C}$. The numerical simulations have been based on the measured geometrical dimensions of the cross sections, the longitudinal imperfections, i. e., the out of straightness of the beams, the residual stresses and the yield strength. The Eurocode simple model promotes ultimate loads that depend mainly on the non-dimensional slenderness of the beams. The analytical results provided by the Eurocode 3, for a certain range of the slenderness, appear to be unsafe when compared with the numerical and experimental results. It is shown that the new proposal is safer than the Eurocode 3 formulas.
\end{abstract}




\section{NOMENCLATURE}

a Maximum amplitude of the beam lateral imperfection

E Young's modulus of elasticity

G Shear modulus of elasticity

$I_{x}, I_{y} \quad$ Second moments of area about the $x, y$ axes

$I_{t} \quad$ Torsion section constant

$I_{w} \quad$ Warping section constant

$f_{y} \quad$ Yield strength

$k \quad$ Effective length factor

$k_{w} \quad$ Warping effective length factor

$k_{y, \theta, c o m} \quad$ Reduction factor for the yield strength at the maximum temperature in the compression flange $\theta_{a, c o m}$, reached at time $t$

$k_{E, \theta, c o m} \quad$ Reduction factor for the slope of the linear elastic range at the maximum steel temperature in the compression flange $\theta_{a, c o m}$ reached at time $t$

$L \quad$ Length of the beams

$M_{b, f i, t, R d} \quad$ Buckling resistance moment in the fire design situation

$M_{c r} \quad$ Elastic critical moment for lateral-torsional buckling

$M_{f i, \theta, R d} \quad$ Design moment resistance of a Class 1 or 2 cross-section with a uniform temperature $\theta_{a}$

$M_{\text {SAFIR }} \quad$ Buckling resistance moment in the fire design situation given by SAFIR

$M_{R d} \quad$ Plastic moment resistance of the gross cross-section, $M_{p l, R d}$ for normal temperature 
$M_{x} \quad$ Bending moment about $x$ axe

$t \quad$ Time

$u \quad$ Lateral displacement

$v \quad$ Vertical displacement

$w_{p l, y} \quad$ Plastic section modulus

$x, y \quad$ Principal centroidal axe

$z \quad$ Longitudinal axis through centroid

\section{Greek}

$\alpha \quad$ Imperfection factor

$\alpha_{M} \quad$ Buckling factor

$\beta \quad$ Severity factor

$\delta \quad$ Central deflection

$\varepsilon \quad$ Material Factor

$\gamma_{M 0} \quad$ Partial safety factor (usually $\gamma_{M 0}=1.0$ )

$\gamma_{M, f i} \quad$ Partial safety factor for the fire situation (usually $\gamma_{M, f i}=1.0$ )

$\theta \quad$ Rotation

$\phi \quad$ Twist rotation

$\lambda_{L T} \quad$ Slenderness

$\bar{\lambda}_{L T} \quad$ Non-dimensional slenderness at room temperature

$\bar{\lambda}_{L T, \theta, c o m}$ Non-dimensional slenderness for the maximum temperature in the compression flange $\theta_{a, c o n t}$

$\bar{\lambda}_{L T, f i} \quad$ Non-dimensional slenderness in the fire design situation

$\chi_{L T, f i} \quad$ Reduction factor for lateral-torsional buckling in the fire design situation 


\section{INTRODUCTION}

The behaviour of steel I-beams at elevated temperatures has been analysed numerically ${ }^{1}$ 2 leading to a new proposal for the evaluation of the lateral-torsional buckling resistance. This new proposal contains a scalar $\beta$ that has to be calibrated to ensure an appropriate safety level, which is done in this work throughout a large set of experimental tests and numerical simulations.

Although the problem of lateral-torsional buckling of steel I-beams at room temperature is well $\mathrm{known}^{3-6}$ the same problem at elevated temperature is not. Among the work done in this field there is the paper by Bayley et al. $^{7}$, who use a three dimensional computer model to investigate the ultimate behaviour of uniformly heated unrestrained beams. In their work the computed failure temperature is related to the degree of utilization when compared with the same temperature given by the Codes, but no analytical proposal is made for the lateral-torsional buckling resistance moment in fire situation. Nevertheless the results presented indicate that the Eurocode 3 Part $1.2^{8}$ overestimates the critical temperature for unrestrained simple beams in fire resistance calculations, which is in accordance with the results of the authors for a certain range of the slenderness, as shown later in this paper.

The proposal the present paper pretends to validate was based on the numerical results from the SAFIR program ${ }^{9}$, a geometrical and materially non-linear code specially established to analyse three-dimensional structures, including the effect of warping, in case of fire. The capability of this code to model the lateral-torsional buckling of beams has been demonstrated ${ }^{10}$ at room temperature by comparisons against the formulas of the Eurocode 3, Part $1-1^{11}$. Franssen ${ }^{12}$ has also compared the SAFIR program with four other structural codes in the case of plane buckling of steel heated columns. The 
program is capable of considering loads placed at any level on a cross-section and it is also possible to introduce residual stresses owing to the fibre type finite element used.

It must be emphasized that the simple model that this paper wants to validate, presented by Vila Real et al. ${ }^{1,2}$, was established on the base of numerical simulations using characteristic values for initial out-of-straightness (L/1000) and residual stresses $(0.3 \times 235 \mathrm{MPa})$, which are unlikely to be simultaneously present in a test or in a real building. In the experimental work, the geometrical imperfections and the residual stresses were measured as well as the nominal yield strength of the material and the Young Modulus. These measured values were used in the numerical calculations.

A set of 120 full-scale tests based on a reaction frame and on a hydraulic system has been carried out for beams of the European series IPE 100 with lengths varying from 0.5 to 6.5 meters. Three tests have been done for each beam length and for each temperature level, due to statistics requirements. The beams were electrically heated by means of ceramic mat elements, heated by a power unit of $70 \mathrm{kVA}$. A ceramic fibre mat was used around the beam and the heating elements in order to increase the thermal efficiency.

\section{EXPERIMENTAL AND NUMERICAL CASE STUDY}

A simply supported beam with fork supports shown in Fig. 1 has been studied. In this figure, $q_{b}$ represents the self weight of the beam and $q$ represents the additional distributed load due to the weight of the ceramic mat and electro-ceramic resistances used.

The experimental set-up is also shown in Fig. 2, where the fork supports, the hydraulic jacks and the ceramic mat elements can be seen. Automatic control of separated heating 
elements was used in order to ensure a uniform temperature distribution along the length of the beams. The temperature was measured with thermocouples welded on the beams at different points of the beam length.

Three types of mid span displacements were experimentally measured as shown in Fig.

3. The vertical displacement, DV, the lateral bottom displacement, DLB and the lateral top displacement, DLC.

The thermal action was changed from room temperature up to $200,300,400,500$ and $600{ }^{\circ} \mathrm{C}$. These temperatures were applied before the mechanical action, with the longitudinal displacement unrestrained and kept eonstant during the loading, which is applied only after the temperature stabilisation.

The vertical and lateral displacements vary in a way that is schematised in Fig. 4. As long as the load on the beam remains bellow the critical value, the beam is stable. However, as the load is increased a critical value is reached when slightly deflected and twisted form of equilibrium becomes possible. The initial plane beam configuration is now unstable, and the lowest load at which this deflected condition occurs is called the beam critical load.

The stress strain relationship used in the numerical simulation of the experimental tests is a function of the measured material strength and varies with temperature, according to Eurocode 3, Part 1-2

A three-dimensional beam element with 15 degrees of freedom and three nodes has been used to numerically simulate the behaviour and the buckling moment resistance of the beams loaded as shown in Fig. 1. 


\subsection{Lateral torsional buckling according to the Eurocode 3}

The design buckling resistance moment of a laterally unrestrained beam with a class 1 or 2 cross section type, in case of fire is given in the Eurocode 3 , Part $1.2^{8}$ by

$$
M_{b, f, t, R d}=\frac{\chi_{L T, f i}}{1.2} w_{p l, y} k_{y, \theta, c o m} f_{y} \frac{1}{\gamma_{M, f i}}
$$

where:

$$
\begin{aligned}
& \chi_{L T, f i} \text { is the reduction factor for lateral-torsional buckling in the fire } \\
& \text { design situation, given by } \\
& \chi_{L T, f i}=\frac{1}{\phi_{L T, \theta, c o m}+\sqrt{\left[\phi_{L T, \theta, c o m}\right]^{2}-\left[\bar{\lambda}_{L T, \theta, c o m}\right]^{2}}} \\
& \text { and } \\
& \phi_{L T, \theta, c o m}=\frac{1}{2}\left[1+\alpha\left(\bar{\lambda}_{L T, \theta, c o m}-0.2\right)+\left(\bar{\lambda}_{L T, \theta, c o m}\right)^{2}\right] \\
& \text { is the plastic section modulus; } \\
& w_{p l, y} \quad \text { is the reduction factor for the yield strength at the maximum } \\
& k_{y, \theta, c o m} \quad \text { temperature in the compression flange } \theta_{a, c o m} \text {, reached at time } t ; \\
& \text { is the partial safety factor for the fire situation (usually } \left.\gamma_{M, f i}=1\right) . \\
& \gamma_{M, f i}
\end{aligned}
$$

The equation (1) is used if the non-dimensional slenderness $\bar{\lambda}_{L T, \theta, c o m}$ for the temperature reached at time $t$, exceeds the value of 0.4 . If the slenderness is lower than this threshold value, it is considered that no lateral buckling will occur and the full plastic bending resistance is considered. 
The constant 1.2 is an empirically determined value and is used as a correction factor that allows for a number of effects.

The reduction factor for lateral-torsional buckling in fire design situation, $\chi_{L T, f i}$, must be determined in the same way as it is at room temperature, but using the nondimensional slenderness $\bar{\lambda}_{L T, \theta, \text { com }}$ (or $\bar{\lambda}_{L T, f i}$, if the temperature field in the cross section is uniform) given by

$$
\bar{\lambda}_{L T, \theta, c o m}=\bar{\lambda}_{L T, f i}=\bar{\lambda}_{L T} \sqrt{\frac{k_{y, \theta, c o m}}{k_{E, \theta, c o m}}}
$$

where

$\bar{\lambda}_{L T}$ is the non-dimensional slenderness at room temperature given by $^{11}$ (for Class 1 or Class 2 cross-sections)

$$
\bar{\lambda}_{L T}=\frac{\lambda_{L T}}{\lambda_{1}}
$$

where

$$
\begin{aligned}
& \lambda_{1}=\pi \sqrt{\frac{E}{f_{y}}} \\
& \lambda_{L T}=\pi \sqrt{\frac{E w_{p l, y}}{M_{c r}}}
\end{aligned}
$$

where $M_{c r}$ is the elastic critical moment for lateral-torsional buckling of the beam. Substituting from (6) and (7) in (5)

$$
\bar{\lambda}_{L T}=\sqrt{\frac{w_{p l, y} f_{y}}{M_{c r}}}=\sqrt{\frac{M_{p l}}{M_{c r}}}
$$

where $M_{p l}$ is the plastic moment resistance of the gross crosssection; 
$k_{E, \theta, c o m} \quad$ is the reduction factor for the slope of the linear elastic range at the maximum steel temperature reached at time $t$.

The imperfection parameter $\alpha$ on equation (3) depends on the type of cross section, being 0.21 for hot rolled sections or 0.49 for welded cross section ${ }^{8}$.

\subsection{The new proposal}

A new proposal for the lateral-torsional buckling resistance, based on numerical calculations was proposed by Vila Real et al. ${ }^{1,2}$. According to this new proposal, and adopting for the lateral-torsional buckling a similar proposal as the one that Franssen et al. ${ }^{13}$ used to represent the behaviour of axially-loaded columns when submitted to fire conditions, the design buckling resistance moment of a laterally unrestrained beam with a class 1 or 2 cross section type, can be calculated by

$$
M_{b, f i, t, R d}=\chi_{L T, f i} w_{p l, y} k_{y, \theta, c o m} f_{y} \frac{1}{\gamma_{M, f i}}
$$

where $\chi_{L T, f i}$, is given by

$$
\chi_{L T, f i}=\frac{1}{\phi_{L T, \theta, c o m}+\sqrt{\left[\phi_{L T, \theta, c o m}\right]^{2}-\left[\bar{\lambda}_{L T, \theta, c o m}\right]^{2}}}
$$

with

$$
\phi_{L T, \theta, c o m}=\frac{1}{2}\left[1+\alpha \bar{\lambda}_{L T, \theta, c o m}+\left(\bar{\lambda}_{L T, \theta, c o m}\right)^{2}\right]
$$

The imperfection factor $\alpha$, in this proposal, is a function of a severity factor $\beta$

$$
\alpha=\beta \varepsilon
$$

The severity factor $\beta$, which should be chosen in order to ensure an appropriate safety level, has been taken as $0.65^{1,2}$, and the material factor $\varepsilon$ is given by 


$$
\varepsilon=\sqrt{\frac{235}{f_{y}}}
$$

where $f_{y}$ represents the nominal yield strength of the material in $\mathrm{MPa}$.

The remaining factors should be calculated as in the Eurocode $3^{8}$.

A comparison between this new proposal and the Eurocode 3 formulas is made on Fig.

5. In this figure on the vertical axis the following ratio is marked:

$$
\frac{M_{b, f i, t, R d}}{M_{f i, \theta, R d}}=\chi_{L T, f i}
$$

where, $M_{b, f i, t, R d}$ is given by equation (1) or equation (9) and $M_{f i, \theta, R d}$ is the design moment resistance of a Class 1 or 2 cross-section with a uniform temperature $\theta_{a}$ given by

$$
M_{f i, \theta, R d}=k_{y, \theta} \frac{\gamma_{M 0}}{\gamma_{M, f i}} M_{R d}
$$

where, $\gamma_{M 0}=1.0, \gamma_{M, f i}=1.0$ and $M_{R d}$ is the plastic resistance of the gross crosssection, $M_{p l, R d}$, for normal temperature, which is given, using $\gamma_{M 0}=1.0$, by

$$
M_{R d}=\frac{w_{p l, y} f_{y}}{\gamma_{M 0}}
$$

It can be verified on Fig. 5 that the shape of the buckling curve is different, with the new one starting from $\chi_{L T, f i}=1.0$ for $\bar{\lambda}_{L T, f i}=0.0$ but decreasing even for very low slenderness, instead of having a horizontal plateau up to $\bar{\lambda}_{L T, f i}=0.4$ as in the present version of the Eurocode $3^{8}$.

The lateral-torsional buckling curve now depends on the steel grade due to the parameter $\varepsilon$ that appears in the imperfection factor as it can be seen in equation (13) and on Fig. 5. 


\section{CRITICAL MOMENT}

The critical moment, $M_{c r}$, necessary to evaluate the non-dimensional slenderness $\bar{\lambda}_{L T, \theta, c o m}$, according the Eurocode 3 is obtained solving the following differential equations ${ }^{5,6}$

$$
\begin{array}{cl} 
& \left(E I_{y} u^{\prime \prime}\right)^{\prime \prime}+\left(M_{x} \phi\right)^{\prime \prime}=0 \\
& \left(E I_{w} \phi^{\prime \prime}\right)^{\prime \prime}-\left(G I_{t} \phi^{\prime}\right)^{\prime}+\left(M_{x} u^{\prime \prime}\right)=0
\end{array}
$$

which traduce the lateral-torsional buckling equilibrium of the beam. The first equation represents the equality at equilibrium between the out-of-plane bending action $-\left(M_{x} \phi\right)^{\prime \prime}$ and the flexural resistance $\left(E I_{y} u^{\prime \prime}\right)^{\prime \prime}$ and the second equation represents the equality between the torsion action $-M_{x} u^{\prime \prime}$, and the warping and torsional resistances $\left(E I_{w} \phi^{\prime \prime}\right)^{\prime \prime}$ and $-\left(G I_{t} \phi^{\prime}\right)^{\prime}$. The bending moment distribution $M_{x}$ due to the transverse load $q$ varies along the beam and so the differential equations have some variable coefficients and are difficult to solve ${ }^{5}$.

It can be verified that these differential equations are satisfied by the substitution of the buckled shapes formulas:

$$
\frac{u}{\delta}=\frac{\phi}{\theta}=\frac{z}{L}-\frac{z^{2}}{L^{2}} \quad \mu \quad \frac{\phi}{S}=\sin \left(\frac{\pi z}{L}\right)
$$

where $\delta$ and $\theta$ represent the values of $u$ and $\phi$ at mid-span and $z$ represents the coordinate along the beam axis.

Substituting the equation (18) and all the derivatives into the following energy equation

$$
\frac{1}{2} \int_{0}^{L}\left(E I_{y} u^{\prime \prime 2}+E I_{w} \phi^{\prime 2}+G I_{t} \phi^{\prime 2}\right) d z+\frac{1}{2} \int_{0}^{L} 2 M_{x} \phi u^{\prime \prime} d z+\frac{1}{2} \int_{0}^{L} q\left(y_{q}-y_{0}\right) \phi^{2} d z=0
$$


and taking into account the moment distribution along the buckling length due to the uniformly distributed load, it can be verified that the critical load F (see Fig. 1) is function of the material properties, the beam cross section geometric characteristics and also function of the distributed load. This critical force $F$ when introduced into the moment distribution, gives the critical moment, $M_{c r}$, at the supports. This moment can be compared to the critical elastic moment, $M_{c r}^{p b}$ for the pure bending case using the moment distribution factor $\alpha_{M}{ }^{5,6}$ as shown in the following equation

$$
M_{c r}=\alpha_{M} M_{c r}^{p b}=\alpha_{M} \frac{\pi^{2} E I_{y}}{(k L)^{2}} \sqrt{\left(\frac{k}{k_{w}}\right)^{2} \frac{I_{w}}{I_{y}}+\frac{(k L)^{2} G I_{t}}{\pi^{2} E I_{y}}}
$$

where $k$ represents the effective lateral buckling length factor and $k_{w}$ the factor which accounts for the beam end warping. Regarding the type of loading and support conditions used in the experimental tests, the value of $k=0.5$ has been used to represent the total restraint of the lateral movement due to the load application process (see Fig. 6) and the value of $k_{w}=1$ to the free end warping condition.

Fig. 7 shows the plan view of the one half deformed beam obtained numerically. It is clearly shown that when the load application point is laterally restrained the effective lateral buckling length factor $k$ must be approximately taken as 0.5 .

The deformed shape of the beam obtained in the experimental tests is shown in Fig. 8. The analytical calculations have shown that the moment distribution factor $\alpha_{M}$ is not constant and depends on the buckling length of the tested beam as shown in Fig. 9. 
A multifunction reaction structure (Fig. 2) was used to test the beams at elevated temperatures and to apply the mechanical loads. The loads were applied by means of two hydraulic jacks with $600 \mathrm{kN}$ of capacity each and the beams were heated using electric ceramic mats.

Five hundred meters of IPE 100 profile was used, giving 120 beams with lengths varying from 0.5 to 6.5 meters.

\subsection{Residuall stresses}

The magnitude and geometric distribution of the residual stresses may vary with the geometry of the cross section and with the straightening and cooling processes. The residual stresses were measured at four points (f1, f2, w1 and w2) as it is shown in Fig. 10.

The measurements were based on the drill hole method. Strain gauges were used and it was necessary to introduce a mechanical interference in the system. The requirement of keeping the disturbance as small as possible is a positive factor in this method. The drill hole rosette requires a small drill hole of about $1.5 \mathrm{~mm}$ in diameter. This can be regarded as a non-destructive technique [14].

The residual stresses were measured on 10 different beams. Some of the measurements were not taken into account because the drilling tool broke. The average measured values were used to represent the residual state of the tested beams and are listed in table 1.

\subsection{Geometric Imperfections}


Two types of geometric imperfections were measured. One related to the cross section dimensions, measured by digital callipers and the other related to the longitudinal lateral distance from an imaginary straight line, measured by a laser beam method. In the numerical modelling, the measured longitudinal imperfections of the beams have been approximated by the following expression

$$
u(z)=a \sin \left(\frac{\pi \times z}{L}\right)
$$

where $a$ is the measured maximum amplitude of the lateral imperfection, as is listed in table 2.

The cross section geometry imperfections were also measured and used in the numerical calculation.

A set of 31 profiles from the originals 46 was used to measure the cross section dimension as shown in table 3 . The calculated plastic modulus exceeds the foreseen values based on nominal dimensions.

\subsection{Material strength characterisation}

A set of 20 tensile specimens extracted from the beams (see Fig. 11) was tested. The specimens were taken from the flange and web parts of the IPE100 beams, and follow the Portuguese standard NP EN10002-1 [15]. Yield strength and elastic modulus evaluation are listed in table 4, with its average values being respectively $320 \mathrm{Mpa}$ and $221 \mathrm{GPa}$.

\subsection{Thermal action}


Two different types of electro ceramic mat resistances measuring $1220 \times 45$ and $610 \times 85 \mathrm{~mm}$, with a maximum electric power of $2.7 \mathrm{~kW}$ each were used to heat the beams. This material is able to support temperatures up to $1050{ }^{\circ} \mathrm{C}$, although the experiments were conducted up to $600^{\circ} \mathrm{C}$ only and with a heat rate of $800{ }^{\circ} \mathrm{C} / \mathrm{h}$.

\subsection{Lateral buckling resistance moments}

The mechanical load was imposed as shown in Fig. 1. After temperature stabilisation a concentrated load F was increased by amounts of $2000 \mathrm{~N}$ until a certain value in which an increase in the displacement value didn't correspond to a load increase.

The experimental lateral buckling resistance moments are shown in figure 12 for temperatures varying from room temperature up to $600{ }^{\circ} \mathrm{C}$.

Experimental results for tested temperatures above $400{ }^{\circ} \mathrm{C}$ have been plotted in the same chart as shown in Fig. 13.

\section{NUMERICAL EVALUATION}

A set of 120 numerical calculations was made to calculate the buckling resistance moment at elevated temperatures. A non-linear material and geometrical code, based on two types of finite elements, made the study of the lateral-torsional buckling of the IPE 100 beams possible. Bi-dimensional plane linear elements were used to describe the temperature field in the cross section of the beams resulting from the thermal action. The warping function and the torsion stiffness have been calculated for each temperature level, according to the experimental measurements of the Young modulus and its temperature dependence according to the Eurocode 3. 
The numerical lateral buckling resistance moments are shown in Fig. 14 for temperatures varying from room temperature up to $600^{\circ} \mathrm{C}$.

The resistance moments obtained by numerical simulation for all the temperatures were plotted in the chart in Fig. 15.

\section{EXPERIMENTAL AND NUMERICAL COMPARISONS}

Both experimental and numerical results have been compared with the simple formulas from Eurocode 3 Part 1.2 and the new proposal.

The results of these comparisons are shown respectively in Fig. 16 and Fig. 17.

The regression line is much more close to the ideal continuous line in the case of numerical calculation than for the experimental results but in both cases the number of unsafe points is smaller when the new proposal is used. From these figures it is clear that the new proposal with $\beta=0.65$ is safer than the Eurocode 3 .

\section{CONCLUSIONS}

The physical fact that elasticity modulus decreases faster than the yield strength when the temperature increases, plus the fact that the stress-strain relationship at elevated temperature is not the same as at room temperature, produce a modification of the lateral-torsional buckling curve at elevated temperature. The horizontal plateau valid at $20{ }^{\circ} \mathrm{C}$ up to a non-dimensional slenderness of 0.4 vanishes at elevated temperatures.

The severity factor $\beta=0.65$ suggested earlier in a previous work by the authors ${ }^{1,2}$ has 
been confirmed and it was shown that the new proposal for lateral-torsional buckling, is safer than the Eurocode 3 formulas.

\section{ACKNOWLEDGEMENTS}

This work was performed in the course of the research project PRAXIS/P/ECM/14176/1998 sponsored by the Portuguese Foundation for Science and Technology. Special thanks to Prof. Mário Vaz and the enterprise J. Soares Correia are also due. 


\section{REFERENCES}

1. Vila Real, P. M. M. \& Franssen, J.-M., Lateral buckling of steel I beams under fire conditions Comparison between the EUROCODE 3 and the SAFIR code, internal report No. 99/02. Institute of Civil Engineering - Service Ponts et Charpents - of the University of Liege, 1999.

2. Vila Real, P. M. M. \& Franssen, J.-M., Numerical Modelling of Lateral Buckling of Steel I Beams Under Fire Conditions - Comparison with Eurocode 3, Vol. 11, No. 2, Journal of Fire Protection Engineering, USA, 2001, pp. 112-128.

3. Papangelis, J.P.; Trahair, N.S. \& Hancock, G.J., Elastic flexural-torsional buckling of structures by computer; Journal of Computers and Structures, Vol. 68; Pergamon Press; 1998, 125-137.

4. Timoshenko P.S. \& Gere J.M., Theory of elastic stability; McGraw Hill Intern. Editions, 1963.

5. Trahair N.S., Flexural - Torsional Buckling of Structures; E\&FN SPON - Chapman \& Hall; London, 1993.

6. Trahair N.S. \& Bradford, M. A., Flexural - Torsional Buckling of structures; E\&FN SPON Chapman \& Hall; London, 1998.

7. C. G. Bailey, IW. Burgess \& R. J. Plank, The Lateral-torsional Buckling of Unrestrained Steel Beams in Fire, Journal Construct. Steel Research, Vol. 36, 1996, pp. 101-119.

8. CEN ENV 1993-1-2, Eurocode 3-Design of steel structures - Part 1-2: General Rules-Structural fire design, 1995.

9. D. I. Nwosu, V. K. R. Kodur, J.-M. Franssen \& J. K. Hum, User Manual for SAFIR. A Computer Program for Analysis of Structures at Elevated Temperature Conditions, National Research Council Canada, int. Report 782, 1999, pp 69.

10. Vila Real, P. M. M. \& Franssen, J.-M., Lateral buckling of steel I beams at room temperature Comparison between the EUROCODE 3 and the SAFIR code considering or not the residual stresses, internal report No. 99/01, University of Liege, 1999.

11. CEN ENV 1993-1-1, Eurocode 3, Design of Steel Structures - Part 1-1: General rules and rules for buildings, 1992.

12. Franssen, J.-M.; Schleich, J. B.; Talamona, Didier; Twilt, L. \& Both K., A comparison between five structural fire codes applied to steel elements, Proc., $4^{\text {th }}$ Int. Symp. On Fire Safety Science, T. Kashiwagi, ed., IAFSS, Boston, Mass., 1994, 1125-1136.

13. Franssen, J.-M.; Schleich, J. B. \& Cajot, L.-G., A simple model for fire resistance of axially-loaded members according to Eurocode 3; Journal of Constructional Steel Research, Vol. 35; 1995, pp. 4969.

14. Hoffman Karl; An introduction to measurements using strain gages; HBM publisher; Germany; 1989.

15. NP EN 10 002-1; CT12, Metallic Materials: Tensile Tests. Part 1: Test Methodology; Portuguese Institute for Quality; (in Portuguese) 1990. 


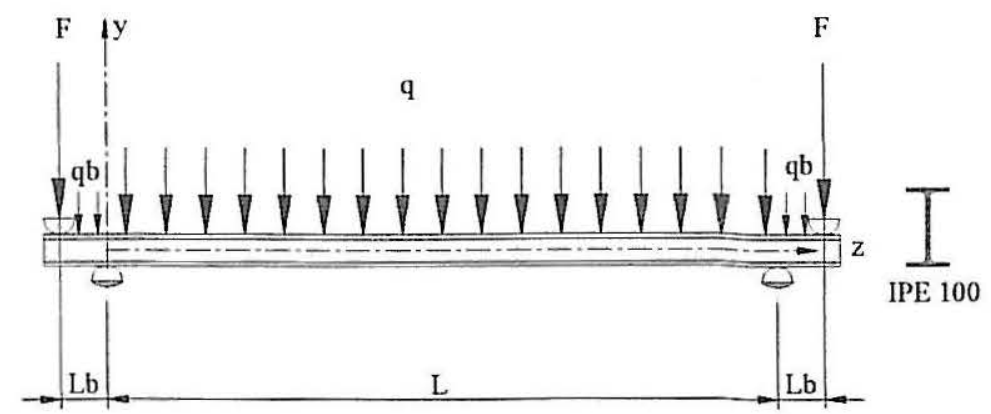

Fig. 1. Case study. Simply supported beam with forks supports. 


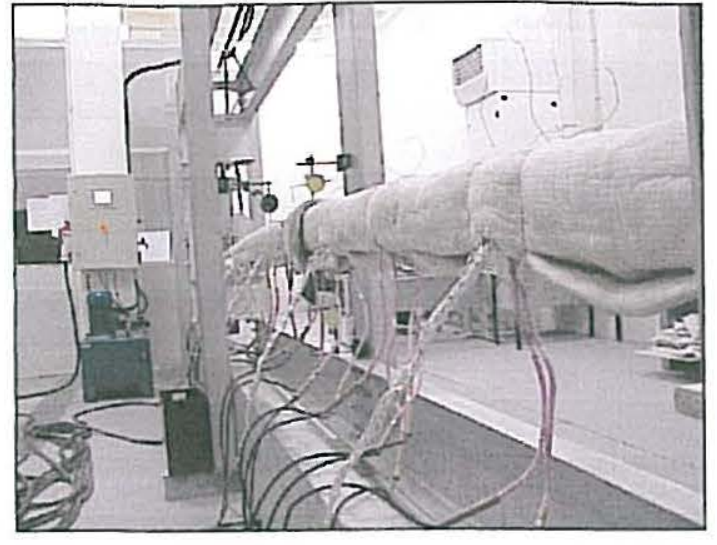

a)

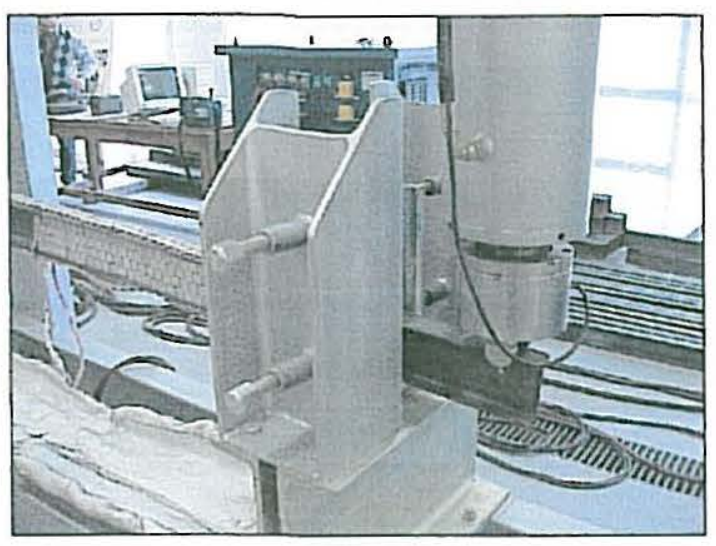

b)

Fig. 2. a) Experimental set up. b) Fork support and hydraulic jack. 


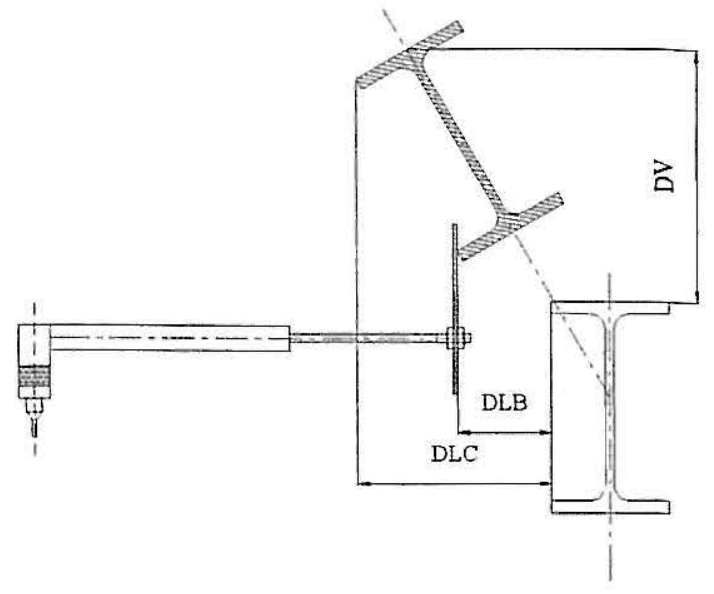

Fig. 3. Measured mid span beam displacements. 

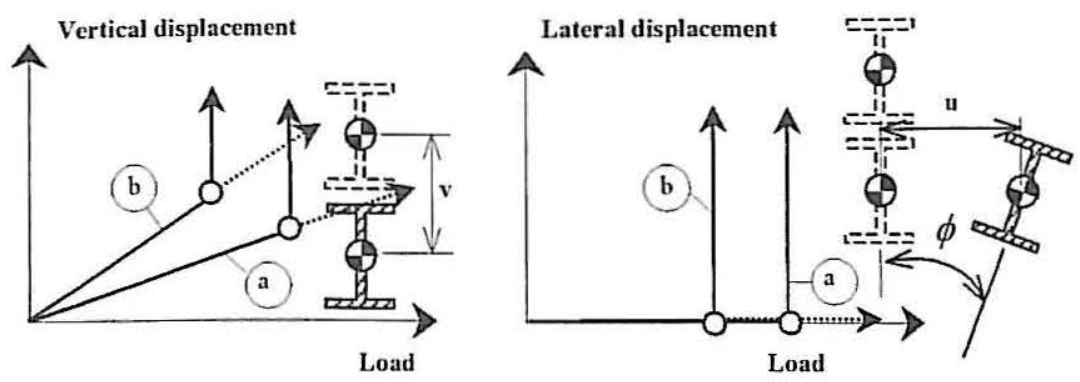

Fig. 4. Load versus mid plane displacements; $a$ - room temperature, b - elevated temperatures. 


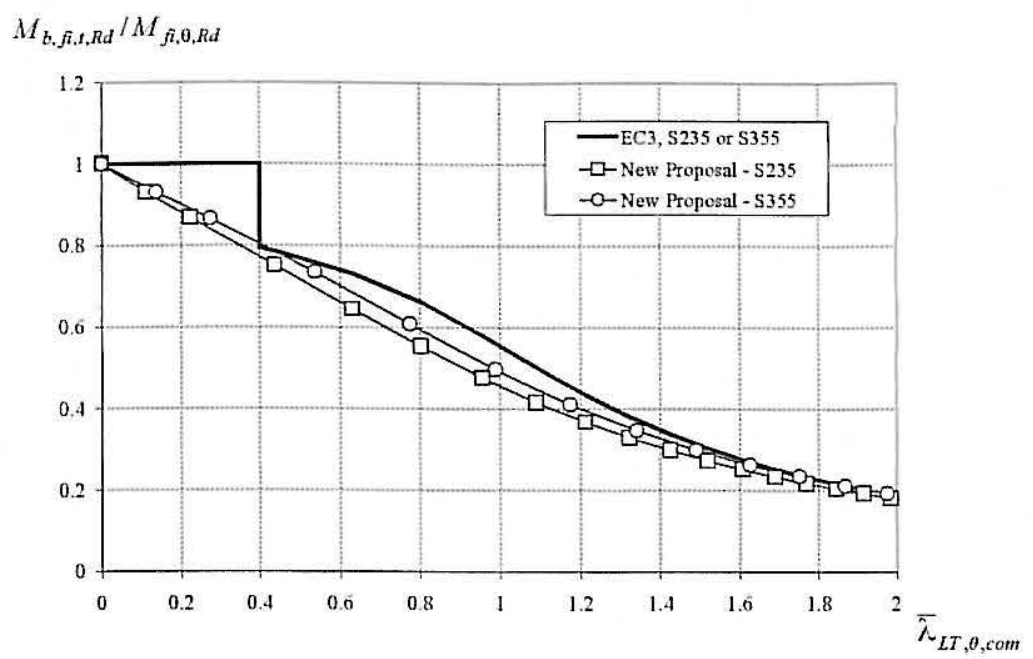

Fig. 5. Comparison between design buckling curve from EC3 and the new proposal. 


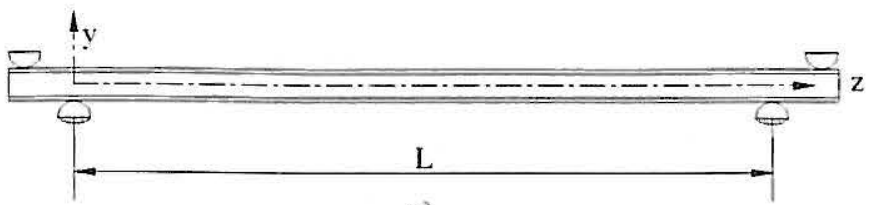

a)

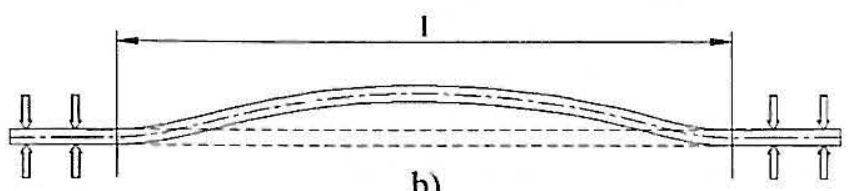

b)

Fig. 6. Effective lateral buckling length, $l=k L$.

a) Elevation; b) Plan 


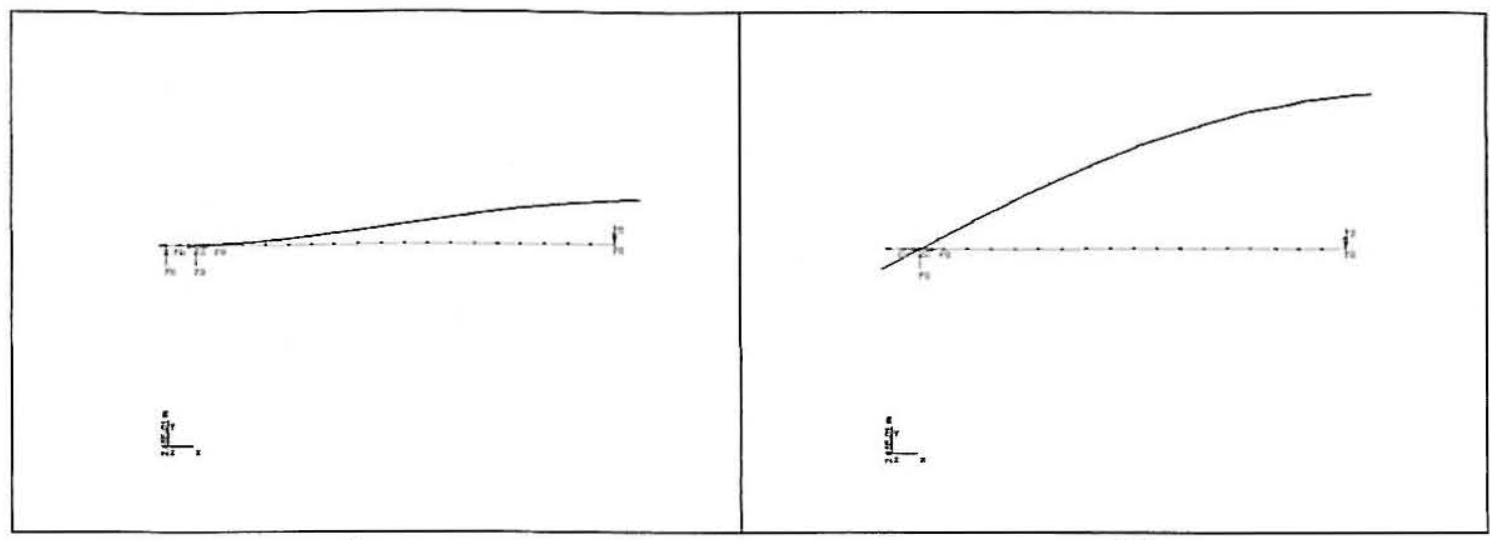

a)

b)

Fig. 7. Plan view from the lateral deformation of the beam at $600^{\circ} \mathrm{C}$ (displacements amplified by a factor 20). a) Restrained lateral movement; b) Unrestrained lateral movement. 


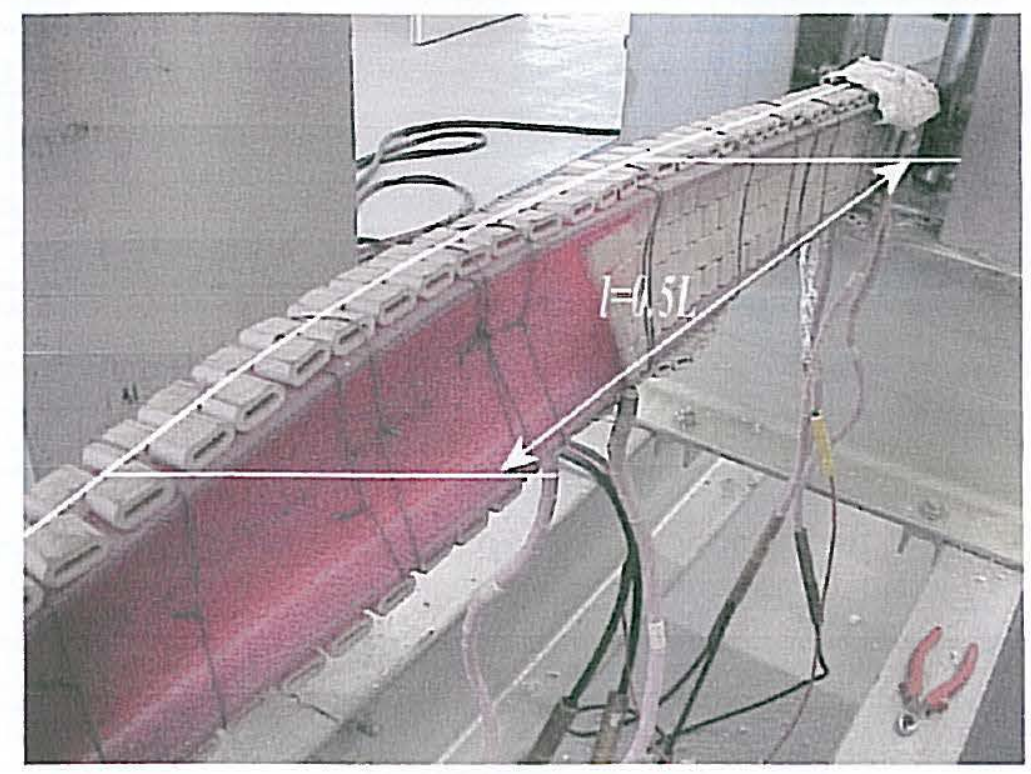

Fig. 8. Deformed beam after heated to $600^{\circ} \mathrm{C}$. Experimental test. 


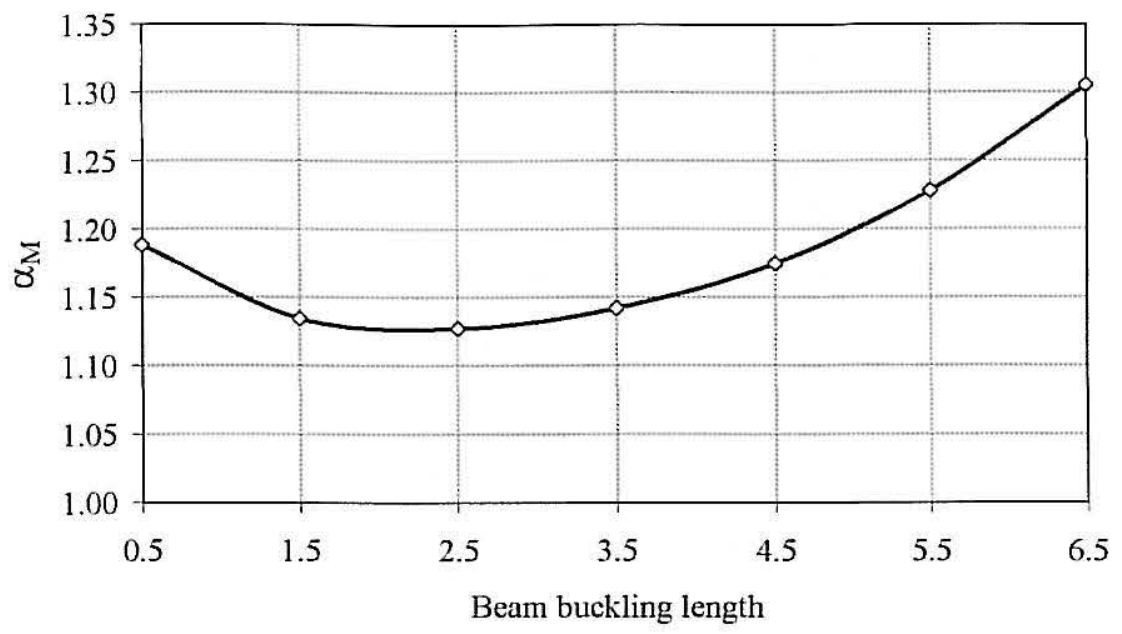

Fig. 9. Moment distribution factor $\alpha_{M}$ (length in meters). 


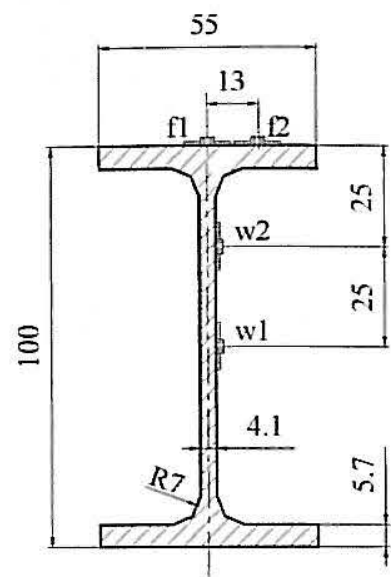

a)

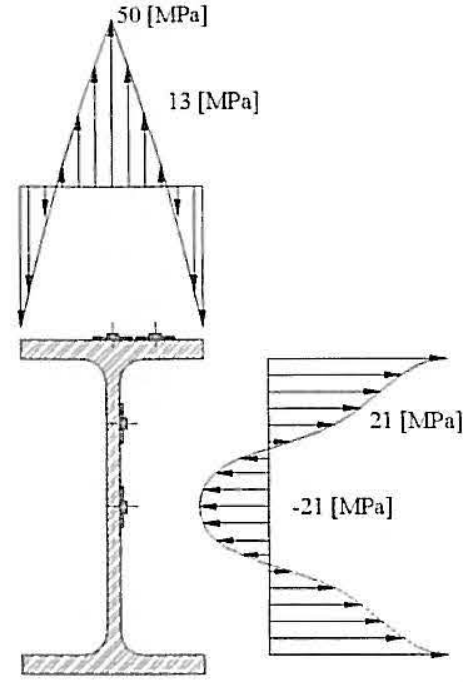

b)

Fig. 10. a) Points of measurement of the residual stresses. b) Assumed distribution of the residual stresses. 


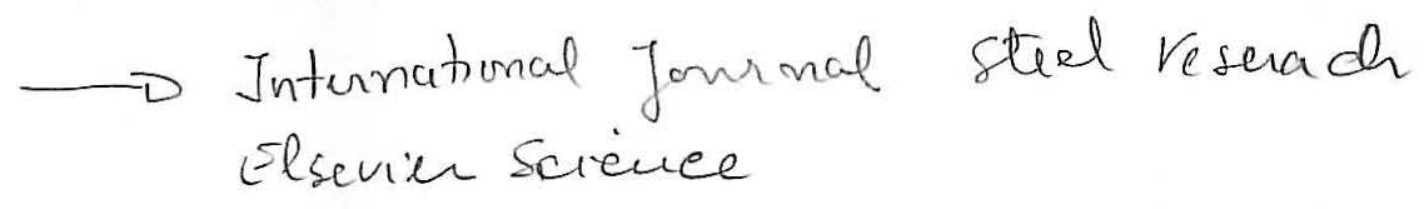

\title{
A New Proposal of a Simple Model for the Lateral-torsional Buckling of Unrestrained Steel I-Beams in case of Fire: Experimental and
}

\author{
Numerical Validation
}

\author{
Vila Real, P. M. M. ${ }^{a^{*}}$; Piloto, P. A. G. ${ }^{b}$ and Franssen, J.-M. ${ }^{c}$ \\ ${ }^{a}$ Department of Civil Engineering, University of Aveiro, \\ 3810 Aveiro, Portugal \\ Tel.: +351-234-370049; fax: +351-234-370094; e-mail: pvreal@civil.ua.pt \\ * Corresponding author \\ ${ }^{b}$ Department of Mechanical Engineering, Polytechnic of Bragança, Portugal \\ ${ }^{c}$ Department Civil Engineering, University of Liege, Belgium
}

\begin{abstract}
The behaviour of Steel I-Beams exhibiting lateral-torsional buckling at elevated temperature has been studied by means of experimental and numerical analysis. The authors in an earlier paper have presented an analytical formula for the buckling resistance moment in the fire design situation. This new proposal, different from the actual proposal of the Eurocode 3 Part 1.2 has been validated in this work by comparison with the results from a set of 120 experimental and numerical tests performed on IPE 100 beams, submitted to temperatures varying from room temperature to $600^{\circ} \mathrm{C}$. The numerical simulations have been based on the measured geometrical dimensions of the cross sections, the longitudinal imperfections, $i$. e., the out of straightness of the beams, the residual stresses and the yield strength. The Eurocode simple model promotes ultimate loads that depend mainly on the non-dimensional slenderness of the beams. The analytical results provided by the Eurocode 3, for a certain range of the slenderness, appear to be unsafe when compared with the numerical and experimental results. It is shown that the new proposal is safer than the Eurocode 3 formulas.
\end{abstract}




\section{NOMENCLATURE}

Maximum amplitude of the beam lateral imperfection

E $\quad$ Young's modulus of elasticity

G Shear modulus of elasticity

$I_{x}, I_{y} \quad$ Second moments of area about the $x, y$ axes

$I_{t} \quad$ Torsion section constant

$I_{w} \quad$ Warping section constant

$f_{y} \quad$ Yield strength

$k \quad$ Effective length factor

$k_{w} \quad$ Warping effective length factor

$k_{y, \theta, c o m} \quad$ Reduction factor for the yield strength at the maximum temperature in the compression flange $\theta_{a, c o m}$, reached at time $t$

$k_{E, \theta, c o m} \quad$ Reduction factor for the slope of the linear elastic range at the maximum steel temperature in the compression flange $\theta_{\text {a.com }}$ reached at time $t$

$L \quad$ Length of the beams

$M_{b, f i t, R d} \quad$ Buckling resistance moment in the fire design situation

$M_{c r} \quad$ Elastic critical moment for lateral-torsional buckling

$M_{f i, \theta, R d} \quad$ Design moment resistance of a Class 1 or 2 cross-section with a uniform temperature $\theta_{a}$

$M_{\text {SAFIR }} \quad$ Buckling resistance moment in the fire design situation given by SAFIR

$M_{R d} \quad$ Plastic moment resistance of the gross cross-section, $M_{p l, R d}$ for normal temperature 


$\begin{array}{ll}M_{x} & \text { Bending moment about } x \text { axe } \\ t & \text { Time } \\ u & \text { Lateral displacement } \\ v & \text { Vertical displacement } \\ w_{p l, y} & \text { Plastic section modulus } \\ x, y & \text { Principal centroidal axe } \\ z & \text { Longitudinal axis through centroid }\end{array}$

\section{Greek}

$\alpha \quad$ Imperfection factor

$\alpha_{M} \quad$ Buckling factor

$\beta \quad$ Severity factor

$\delta \quad$ Central deflection

$\varepsilon \quad$ Material Factor

$\gamma_{M 0} \quad$ Partial safety factor (usually $\gamma_{M 0}=1.0$ )

$\gamma_{M, f i} \quad$ Partial safety factor for the fire situation (usually $\gamma_{M, f i}=1.0$ )

$\theta \quad$ Rotation

$\phi \quad$ Twist rotation

$\lambda_{L T} \quad$ Slenderness

$\bar{\lambda}_{L T} \quad$ Non-dimensional slenderness at room temperature

$\bar{\lambda}_{L T, \theta, c o m}$ Non-dimensional slenderness for the maximum temperature in the compression flange $\theta_{a, c o m}$

$\bar{\lambda}_{L T, f i} \quad$ Non-dimensional slenderness in the fire design situation

$\chi_{L T, f i} \quad$ Reduction factor for lateral-torsional buckling in the fire design situation 


\section{INTRODUCTION}

The behaviour of steel I-beams at elevated temperatures has been analysed numerically ${ }^{1,}$ 2 leading to a new proposal for the evaluation of the lateral-torsional buckling resistance. This new proposal contains a scalar $\beta$ that has to be calibrated to ensure an appropriate safety level, which is done in this work throughout a large set of experimental tests and numerical simulations.

Although the problem of lateral-torsional buckling of steel I-beams at room temperature is well known $\mathrm{kn}^{3-6}$ the same problem at elevated temperature is not. Among the work done in this field there is the paper by Bayley et al. $^{7}$, who use a three dimensional computer model to investigate the ultimate behaviour of uniformly heated unrestrained beams. In their work the computed failure temperature is related to the degree of utilization when compared with the same temperature given by the Codes, but no analytical proposal is made for the lateral-torsional buckling resistance moment in fire situation. Nevertheless the results presented indicate that the Eurocode 3 Part $1.2^{8}$ overestimates the critical temperature for unrestrained simple beams in fire resistance calculations, which is in accordance with the results of the authors for a certain range of the slenderness, as shown later in this paper.

The proposal the present paper pretends to validate was based on the numerical results from the SAFIR program ${ }^{9}$, a geometrical and materially non-linear code specially established to analyse three-dimensional structures, including the effect of warping, in case of fire. The capability of this code to model the lateral-torsional buckling of beams has been demonstrated ${ }^{10}$ at room temperature by comparisons against the formulas of the Eurocode 3, Part $1-1^{11}$. Franssen ${ }^{12}$ has also compared the SAFIR program with four other structural codes in the case of plane buckling of steel heated columns. The 
program is capable of considering loads placed at any level on a cross-section and it is also possible to introduce residual stresses owing to the fibre type finite element used.

It must be emphasized that the simple model that this paper wants to validate, presented

by Vila Real et al. ${ }^{1,2}$, was established on the base of numerical simulations using characteristic values for initial out-of-straightness (L/1000) and residual stresses $(0.3 \times 235 \mathrm{MPa})$, which are unlikely to be simultaneously present in a test or in a real building. In the experimental work, the geometrical imperfections and the residual stresses were measured as well as the nominal yield strength of the material and the Young Modulus. These measured values were used in the numerical calculations.

A set of 120 full-scale tests based on a reaction frame and on a hydraulic system has been carried out for beams of the European series IPE 100 with lengths varying from 0.5 to 6.5 meters. Three tests have been done for each beam length and for each temperature level, due to statistics requirements. The beams were electrically heated by means of ceramic mat elements, heated by a power unit of $70 \mathrm{kVA}$. A ceramic fibre mat was used around the beam and the heating elements in order to increase the thermal efficiency.

\section{EXPERIMENTAL AND NUMERICAL CASE STUDY}

A simply supported beam with fork supports shown in Fig. 1 has been studied. In this figure, $q_{b}$ represents the self weight of the beam and $q$ represents the additional distributed load due to the weight of the ceramic mat and electro-ceramic resistances used.

The experimental set-up is also shown in Fig. 2, where the fork supports, the hydraulic jacks and the ceramic mat elements can be seen. Automatic control of separated heating 
elements was used in order to ensure a uniform temperature distribution along the length of the beams. The temperature was measured with thermocouples welded on the beams at different points of the beam length.

Three types of mid span displacements were experimentally measured as shown in Fig. 3. The vertical displacement, DV, the lateral bottom displacement, DLB and the lateral top displacement, DLC.

The thermal action was changed from room temperature up to $200,300,400,500$ and $600{ }^{\circ} \mathrm{C}$. These temperatures were applied before the mechanical action, with the longitudinal displacement unrestrained and kept eonstant during the loading, which is applied only after the temperature stabilisation.

The vertical and lateral displacements vary in a way that is schematised in Fig. 4. As long as the load on the beam remains bellow the critical value, the beam is stable. However, as the load is increased a critical value is reached when slightly deflected and twisted form of equilibrium becomes possible. The initial plane beam configuration is now unstable, and the lowest load at which this deflected condition occurs is called the beam critical load.

The stress strain relationship used in the numerical simulation of the experimental tests is a function of the measured material strength and varies with temperature, according to Eurocode 3, Part $1-2^{8}$.

A three-dimensional beam element with 15 degrees of freedom and three nodes has been used to numerically simulate the behaviour and the buckling moment resistance of the beams loaded as shown in Fig. 1. 


\subsection{Lateral torsional buckling according to the Eurocode 3}

The design buckling resistance moment of a laterally unrestrained beam with a class 1 or 2 cross section type, in case of fire is given in the Eurocode 3, Part $1.2^{8}$ by

$$
M_{b, f i, t, R d}=\frac{\chi_{L T, f i}}{1.2} w_{p l, y} k_{y, \theta, c o m} f_{y} \frac{1}{\gamma_{M, f i}}
$$

where:

$$
\begin{aligned}
& \chi_{L T, f i} \text { is the reduction factor for lateral-torsional buckling in the fire } \\
& \text { design situation, given by } \\
& \quad \chi_{L T, f i}=\frac{1}{\phi_{L T, \theta, c o n}+\sqrt{\left[\phi_{L T, \theta, c o m}\right]^{2}-\left[\bar{\lambda}_{L T, \theta, c o m}\right]^{2}}} \\
& \text { and } \\
& \phi_{L T, \theta, c o m}=\frac{1}{2}\left[1+\alpha\left(\bar{\lambda}_{L T, \theta, c o m}-0.2\right)+\left(\bar{\lambda}_{L T, \theta, c o m}\right)^{2}\right] \\
& \text { is the plastic section modulus; } \\
& w_{p l, y} \quad \text { is the reduction factor for the yield strength at the maximum } \\
& k_{y, \theta, c o m} \quad \text { temperature in the compression flange } \theta_{a, c o m} \text {, reached at time } t ; \\
& \text { is the partial safety factor for the fire situation (usually } \left.\gamma_{M, f i}=1\right) \\
& \gamma_{M, f i}
\end{aligned}
$$

The equation (1) is used if the non-dimensional slenderness $\bar{\lambda}_{L T, \theta, c o m}$ for the temperature reached at time $t$, exceeds the value of 0.4 . If the slenderness is lower than this threshold value, it is considered that no lateral buckling will occur and the full plastic bending resistance is considered. 
The constant 1.2 is an empirically determined value and is used as a correction factor that allows for a number of effects.

The reduction factor for lateral-torsional buckling in fire design situation, $\chi_{L T, f i}$, must be determined in the same way as it is at room temperature, but using the nondimensional slenderness $\bar{\lambda}_{L T, \theta, c o m}$ (or $\bar{\lambda}_{L T, f i}$, if the temperature field in the cross section is uniform) given by

$$
\bar{\lambda}_{L T, \theta, c o m}=\bar{\lambda}_{L T, f i}=\bar{\lambda}_{L T} \sqrt{\frac{k_{y, \theta, c o m}}{k_{E, \theta, c o m}}}
$$

where

$$
\begin{aligned}
& \bar{\lambda}_{L T} \quad \text { is the non-dimensional slenderness at room temperature given } \\
& \text { by }^{11} \text { (for Class } 1 \text { or Class } 2 \text { cross-sections) } \\
& \bar{\lambda}_{L T}=\frac{\lambda_{L T}}{\lambda_{1}}
\end{aligned}
$$

where

$$
\begin{aligned}
& \lambda_{1}=\pi \sqrt{\frac{E}{f_{y}}} \\
& \lambda_{L T}=\pi \sqrt{\frac{E w_{p l, y}}{M_{c r}}}
\end{aligned}
$$

where $M_{c r}$ is the elastic critical moment for lateral-torsional buckling of the beam. Substituting from (6) and (7) in (5)

$$
\bar{\lambda}_{L T}=\sqrt{\frac{w_{p l, y} f_{y}}{M_{c r}}}=\sqrt{\frac{M_{p l}}{M_{c r}}}
$$

where $M_{p l}$ is the plastic moment resistance of the gross crosssection; 
$k_{E, \theta, c o m} \quad$ is the reduction factor for the slope of the linear elastic range at the maximum steel temperature reached at time $t$.

The imperfection parameter $\alpha$ on equation (3) depends on the type of cross section, being 0.21 for hot rolled sections or 0.49 for welded cross section ${ }^{8}$.

\subsection{The new proposal}

A new proposal for the lateral-torsional buckling resistance, based on numerical calculations was proposed by Vila Real et al. ${ }^{1,2}$. According to this new proposal, and adopting for the lateral-torsional buckling a similar proposal as the one that Franssen et al. ${ }^{13}$ used to represent the behaviour of axially-loaded columns when submitted to fire conditions, the design buckling resistance moment of a laterally unrestrained beam with a class 1 or 2 cross section type, can be calculated by

$$
M_{b, f i, t, R d}=\chi_{L T, f i} w_{p l, y} k_{y, \theta, c o m} f_{y} \frac{1}{\gamma_{M, f i}}
$$

where $\chi_{L T, f i}$, is given by

$$
\chi_{L T, f i}=\frac{1}{\phi_{L T, \theta, c o m}+\sqrt{\left[\phi_{L T, \theta, c o m}\right]^{2}-\left[\bar{\lambda}_{L T, \theta, c o m}\right]^{2}}}
$$

with

$$
\phi_{L T, \theta, c o m}=\frac{1}{2}\left[1+\alpha \bar{\lambda}_{L T, \theta, c o m}+\left(\bar{\lambda}_{L T, \theta, c o m}\right)^{2}\right]
$$

The imperfection factor $\alpha$, in this proposal, is a function of a severity factor $\beta$

$$
\alpha=\beta \varepsilon
$$

The severity factor $\beta$, which should be chosen in order to ensure an appropriate safety level, has been taken as $0.65^{1,2}$, and the material factor $\varepsilon$ is given by 


$$
\varepsilon=\sqrt{\frac{235}{f_{y}}}
$$

where $f_{y}$ represents the nominal yield strength of the material in MPa.

The remaining factors should be calculated as in the Eurocode $3^{8}$.

A comparison between this new proposal and the Eurocode 3 formulas is made on Fig.

5. In this figure on the vertical axis the following ratio is marked:

$$
\frac{M_{b, f i, t, R d}}{M_{f i, \theta, R d}}=\chi_{L T, f i}
$$

where, $M_{b, f i, t, R d}$ is given by equation (1) or equation (9) and $M_{f i, \theta, R d}$ is the design moment resistance of a Class 1 or 2 cross-section with a uniform temperature $\theta_{a}$ given by

$$
M_{f i, \theta, R d}=k_{y, \theta} \frac{\gamma_{M 0}}{\gamma_{M, f i}} M_{R d}
$$

where, $\gamma_{M 0}=1.0, \gamma_{M, f i}=1.0$ and $M_{R d}$ is the plastic resistance of the gross crosssection, $M_{p l, R d}$, for normal temperature, which is given, using $\gamma_{M 0}=1.0$, by

$$
M_{R d}=\frac{w_{p l, y} f_{y}}{\gamma_{M 0}}
$$

It can be verified on Fig. 5 that the shape of the buckling curve is different, with the new one starting from $\chi_{L T, f i}=1.0$ for $\bar{\lambda}_{L T, f i}=0.0$ but decreasing even for very low slenderness, instead of having a horizontal plateau up to $\bar{\lambda}_{L T, f i}=0.4$ as in the present version of the Eurocode $3^{8}$.

The lateral-torsional buckling curve now depends on the steel grade due to the parameter $\varepsilon$ that appears in the imperfection factor as it can be seen in equation (13) and on Fig. 5. 


\section{CRITICAL MOMENT}

The critical moment, $M_{c r}$, necessary to evaluate the non-dimensional slenderness $\bar{\lambda}_{L T, \theta, c o n}$, according the Eurocode 3 is obtained solving the following differential equations $s^{5,6}$

$$
\begin{array}{cl} 
& \left(E I_{y} u^{\prime \prime}\right)^{\prime \prime}+\left(M_{x} \phi\right)^{\prime \prime}=0 \\
& \left(E I_{w} \phi^{\prime \prime}\right)^{\prime \prime}-\left(G I_{t} \phi^{\prime}\right)^{\prime}+\left(M_{x} u^{\prime \prime}\right)=0
\end{array}
$$

which traduce the lateral-torsional buckling equilibrium of the beam. The first equation represents the equality at equilibrium between the out-of-plane bending action $-\left(M_{x} \phi\right)^{\prime \prime}$ and the flexural resistance $\left(E I_{y} u^{\prime \prime}\right)^{\prime \prime}$ and the second equation represents the equality between the torsion action $-M_{x} u^{n}$, and the warping and torsional resistances $\left(E I_{w} \phi^{\prime \prime}\right)^{\prime \prime}$ and $-\left(G I_{t} \phi^{\prime}\right)^{\prime}$. The bending moment distribution $M_{x}$ due to the transverse load $q$ varies along the beam and so the differential equations have some variable coefficients and are difficult to solve ${ }^{5}$.

It can be verified that these differential equations are satisfied by the substitution of the buckled shapes formulas:

$$
\frac{u}{\delta}=\frac{\phi}{\theta}=\frac{z}{L}-\frac{z^{2}}{L^{2}} \quad \mu \quad \frac{\phi}{S}=\sin \left(\frac{\pi z}{L}\right)
$$

where $\delta$ and $\theta$ represent the values of $u$ and $\phi$ at mid-span and $z$ represents the coordinate along the beam axis.

Substituting the equation (18) and all the derivatives into the following energy equation

$$
\frac{1}{2} \int_{0}^{L}\left(E I_{y} u^{n 2}+E I_{w} \phi^{n 2}+G I_{t} \phi^{2}\right) d z+\frac{1}{2} \int_{0}^{L} 2 M_{x} \phi u^{n} d z+\frac{1}{2} \int_{0}^{L} q\left(y_{q}-y_{0}\right) \phi^{2} d z=0
$$


and taking into account the moment distribution along the buckling length due to the uniformly distributed load, it can be verified that the critical load F (see Fig. 1) is function of the material properties, the beam cross section geometric characteristics and also function of the distributed load. This critical force $\mathrm{F}$ when introduced into the moment distribution, gives the critical moment, $M_{c r}$, at the supports. This moment can be compared to the critical elastic moment, $M_{c r}^{p b}$ for the pure bending case using the moment distribution factor $\alpha_{M}{ }^{5,6}$ as shown in the following equation

$$
M_{c r}=\alpha_{M} M_{c r}^{p b}=\alpha_{M} \frac{\pi^{2} E I_{y}}{(k L)^{2}} \sqrt{\left(\frac{k}{k_{w}}\right)^{2} \frac{I_{w}}{I_{y}}+\frac{(k L)^{2} G I_{t}}{\pi^{2} E I_{y}}}
$$

where $k$ represents the effective lateral buckling length factor and $k_{w}$ the factor which accounts for the beam end warping. Regarding the type of loading and support conditions used in the experimental tests, the value of $k=0.5$ has been used to represent the total restraint of the lateral movement due to the load application process (see Fig. 6) and the value of $k_{w}=1$ to the free end warping condition.

Fig. 7 shows the plan view of the one half deformed beam obtained numerically. It is clearly shown that when the load application point is laterally restrained the effective lateral buckling length factor $k$ must be approximately taken as 0.5 .

The deformed shape of the beam obtained in the experimental tests is shown in Fig. 8. The analytical calculations have shown that the moment distribution factor $\alpha_{M}$ is not constant and depends on the buckling length of the tested beam as shown in Fig. 9. 
A multifunction reaction structure (Fig. 2) was used to test the beams at elevated temperatures and to apply the mechanical loads. The loads were applied by means of two hydraulic jacks with $600 \mathrm{kN}$ of capacity each and the beams were heated using electric ceramic mats.

Five hundred meters of IPE 100 profile was used, giving 120 beams with lengths varying from 0.5 to 6.5 meters.

\subsection{Residual stresses}

The magnitude and geometric distribution of the residual stresses may vary with the geometry of the cross section and with the straightening and cooling processes. The residual stresses were measured at four points ( $\mathrm{fl}, \mathrm{f2}, \mathrm{w} 1$ and $\mathrm{w} 2)$ as it is shown in Fig. 10.

The measurements were based on the drill hole method. Strain gauges were used and it was necessary to introduce a mechanical interference in the system. The requirement of keeping the disturbance as small as possible is a positive factor in this method. The drill hole rosette requires a small drill hole of about $1.5 \mathrm{~mm}$ in diameter. This can be regarded as a non-destructive technique [14].

The residual stresses were measured on 10 different beams. Some of the measurements were not taken into account because the drilling tool broke. The average measured values were used to represent the residual state of the tested beams and are listed in table 1.

\subsection{Geometric Imperfections}


Two types of geometric imperfections were measured. One related to the cross section dimensions, measured by digital callipers and the other related to the longitudinal lateral distance from an imaginary straight line, measured by a laser beam method. In the numerical modelling, the measured longitudinal imperfections of the beams have been approximated by the following expression

$$
u(z)=a \sin \left(\frac{\pi \times z}{L}\right)
$$

where $a$ is the measured maximum amplitude of the lateral imperfection, as is listed in table 2 .

The cross section geometry imperfections were also measured and used in the numerical calculation.

A set of 31 profiles from the originals 46 was used to measure the cross section dimension as shown in table 3 . The calculated plastic modulus exceeds the foreseen values based on nominal dimensions.

\subsection{Material strength characterisation}

A set of 20 tensile specimens extracted from the beams (see Fig. 11) was tested. The specimens were taken from the flange and web parts of the IPE100 beams, and follow the Portuguese standard NP EN10002-1 [15]. Yield strength and elastic modulus evaluation are listed in table 4, with its average values being respectively $320 \mathrm{Mpa}$ and $221 \mathrm{GPa}$.

\subsection{Thermal action}


Two different types of electro ceramic mat resistances measuring $1220 \times 45$ and $610 \times 85 \mathrm{~mm}$, with a maximum electric power of $2.7 \mathrm{~kW}$ each were used to heat the beams. This material is able to support temperatures up to $1050{ }^{\circ} \mathrm{C}$, although the experiments were conducted up to $600^{\circ} \mathrm{C}$ only and with a heat rate of $800^{\circ} \mathrm{C} / \mathrm{h}$.

\subsection{Lateral buckling resistamce moments}

The mechanical load was imposed as shown in Fig. 1. After temperature stabilisation a concentrated load F was increased by amounts of $2000 \mathrm{~N}$ until a certain value in which an increase in the displacement value didn't correspond to a load increase.

The experimental lateral buckling resistance moments are shown in figure 12 for temperatures varying from room temperature up to $600^{\circ} \mathrm{C}$.

Experimental results for tested temperatures above $400{ }^{\circ} \mathrm{C}$ have been plotted in the same chart as shown in Fig. 13.

\section{NUMERICAL EVALUATION}

A set of 120 numerical calculations was made to calculate the buckling resistance moment at elevated temperatures. A non-linear material and geometrical code, based on two types of finite elements, made the study of the lateral-torsional buckling of the IPE 100 beams possible. Bi-dimensional plane linear elements were used to describe the temperature field in the cross section of the beams resulting from the thermal action. The warping function and the torsion stiffness have been calculated for each temperature level, according to the experimental measurements of the Young modulus and its temperature dependence according to the Eurocode 3. 
The numerical lateral buckling resistance moments are shown in Fig. 14 for temperatures varying from room temperature up to $600{ }^{\circ} \mathrm{C}$.

The resistance moments obtained by numerical simulation for all the temperatures were plotted in the chart in Fig. 15.

\section{EXPERIMENTAL AND NUMERICAL COMPARISONS}

Both experimental and numerical results have been compared with the simple formulas from Eurocode 3 Part 1.2 and the new proposal.

The results of these comparisons are shown respectively in Fig. 16 and Fig. 17.

The regression line is much more close to the ideal continuous line in the case of numerical calculation than for the experimental results but in both cases the number of unsafe points is smaller when the new proposal is used. From these figures it is clear that the new proposal with $\beta=0.65$ is safer than the Eurocode 3 .

\section{CONCLUSIONS}

The physical fact that elasticity modulus decreases faster than the yield strength when the temperature increases, plus the fact that the stress-strain relationship at elevated temperature is not the same as at room temperature, produce a modification of the lateral-torsional buckling curve at elevated temperature. The horizontal plateau valid at $20{ }^{\circ} \mathrm{C}$ up to a non-dimensional slenderness of 0.4 vanishes at elevated temperatures. The severity factor $\beta=0.65$ suggested earlier in a previous work by the authors ${ }^{1,2}$ has 
been confirmed and it was shown that the new proposal for lateral-torsional buckling, is safer than the Eurocode 3 formulas.

\section{ACKNOWLEDGEMENTS}

This work was performed in the course of the research project PRAXIS/P/ECM/14176/1998 sponsored by the Portuguese Foundation for Science and Technology. Special thanks to Prof. Mário Vaz and the enterprise J. Soares Correia are also due. 


\section{REFERENCES}

1. Vila Real, P. M. M. \& Franssen, J.-M., Lateral buckling of steel I beams under fire conditions Comparison between the EUROCODE 3 and the SAFIR code, internal report No. 99/02. Institute of Civil Engineering - Service Ponts et Charpents - of the University of Liege, 1999.

2. Vila Real, P. M. M. \& Franssen, J.-M., Numerical Modelling of Lateral Buckling of Steel I Beams Under Fire Conditions - Comparison with Eurocode 3, Vol. 11, No. 2, Journal of Fire Protection Engineering, USA, 2001, pp. 112-128.

3. Papangelis, J.P.; Trahair, N.S. \& Hancock, G.J., Elastic flexural-torsional buckling of structures by computer; Journal of Computers and Structures, Vol. 68; Pergamon Press; 1998, 125-137.

4. Timoshenko P.S. \& Gere J.M., Theory of elastic stability; McGraw Hill Intern. Editions, 1963.

5. Trahair N.S., Flexural - Torsional Buckling of Structures; E\&FN SPON - Chapman \& Hall; London, 1993.

6. Trahair N.S. \& Bradford, M. A., Flexural - Torsional Buckling of structures; E\&FN SPON Chapman \& Hall; London, 1998.

7. C. G. Bailey, IW. Burgess \& R. J. Plank, The Lateral-torsional Buckling of Unrestrained Steel Beams in Fire, Journal Construct. Steel Research, Vol. 36, 1996, pp. 101-119.

8. CEN ENV 1993-1-2, Eurocode 3 - Design of steel structures - Part 1-2: General Rules - Structural fire design, 1995.

9. D. I. Nwosu, V. K. R. Kodur, J.-M. Franssen \& J. K. Hum, User Manual for SAFIR. A Computer Program for Analysis of Structures at Elevated Temperature Conditions, National Research Council Canada, int. Report 782, 1999, pp 69.

10. Vila Real, P. M. M. \& Franssen, J.-M., Lateral buckling of steel I beams at room temperature Comparison between the EUROCODE 3 and the SAFIR code considering or not the residual stresses, internal report No. 99/01, University of Liege, 1999.

11. CEN ENV 1993-1-1, Eurocode 3, Design of Steel Structures - Part 1-1: General rules and rules for buildings, 1992.

12. Franssen, J.-M.; Schleich, J. B.; Talamona, Didier; Twilt, L. \& Both K., A comparison between five structural fire codes applied to steel elements, Proc., $4^{\text {th }}$ Int. Symp. On Fire Safety Science, T. Kashiwagi, ed., IAFSS, Boston, Mass., 1994, 1125-1136.

13. Franssen, J.-M.; Schleich, J. B. \& Cajot, L.-G., A simple model for fire resistance of axially-loaded members according to Eurocode 3; Journal of Constructional Steel Research, Vol. 35; 1995, pp. 4969.

14. Hoffman Karl; An introduction to measurements using strain gages; HBM publisher; Germany; 1989.

15. NP EN 10 002-1; CT12, Metallic Materials: Tensile Tests. Part 1: Test Methodology; Portuguese Institute for Quality; (in Portuguese) 1990. 


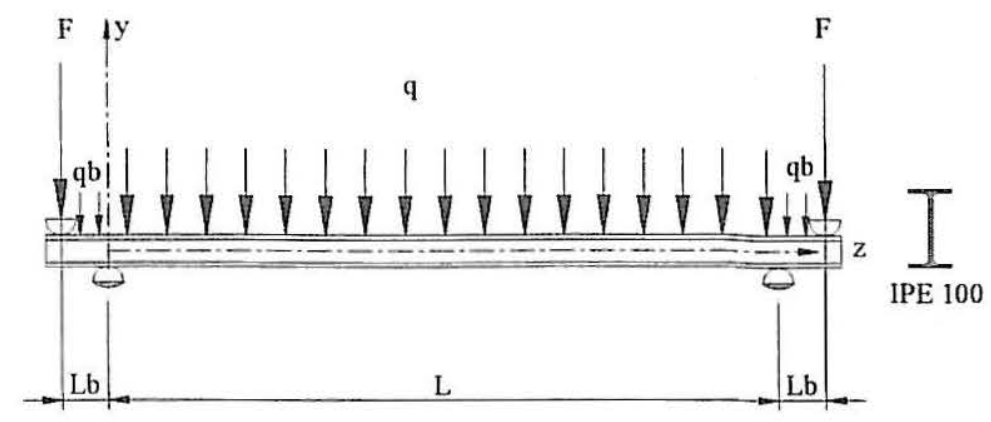

Fig. 1. Case study. Simply supported beam with forks supports. 


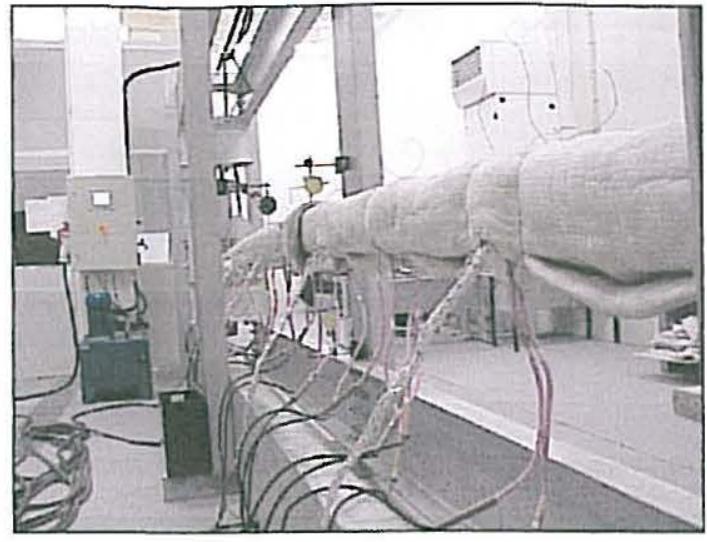

a)

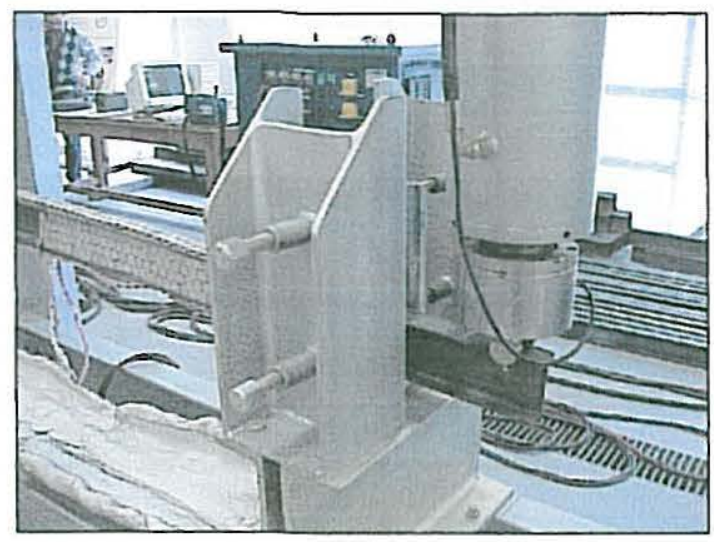

b)

Fig. 2. a) Experimental set up. b) Fork support and hydraulic jack. 


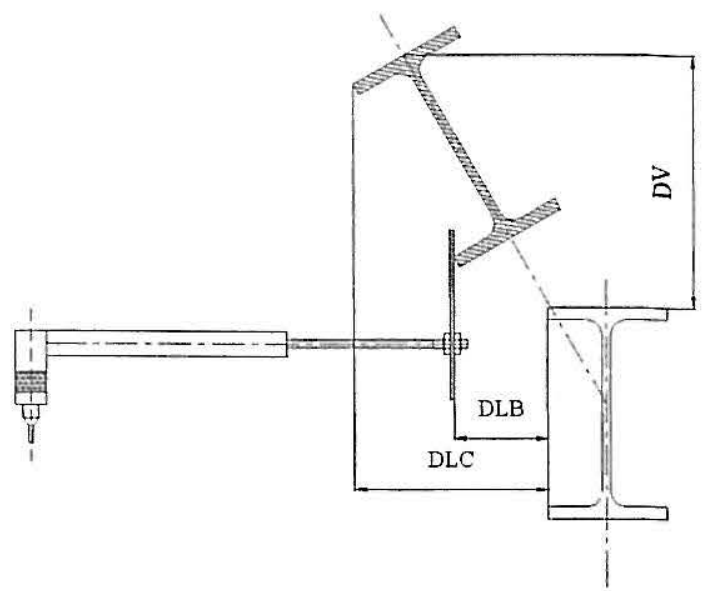

Fig. 3. Measured mid span beam displacements. 

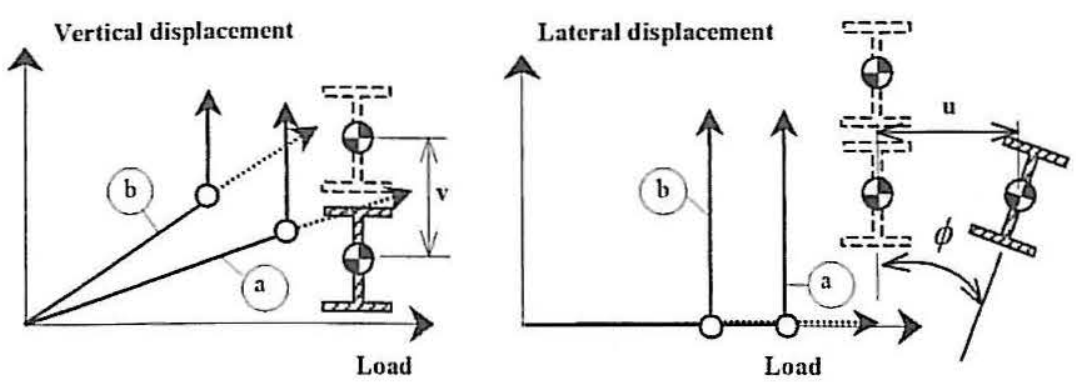

Fig. 4. Load versus mid plane displacements; a - room temperature, b - elevated temperatures. 


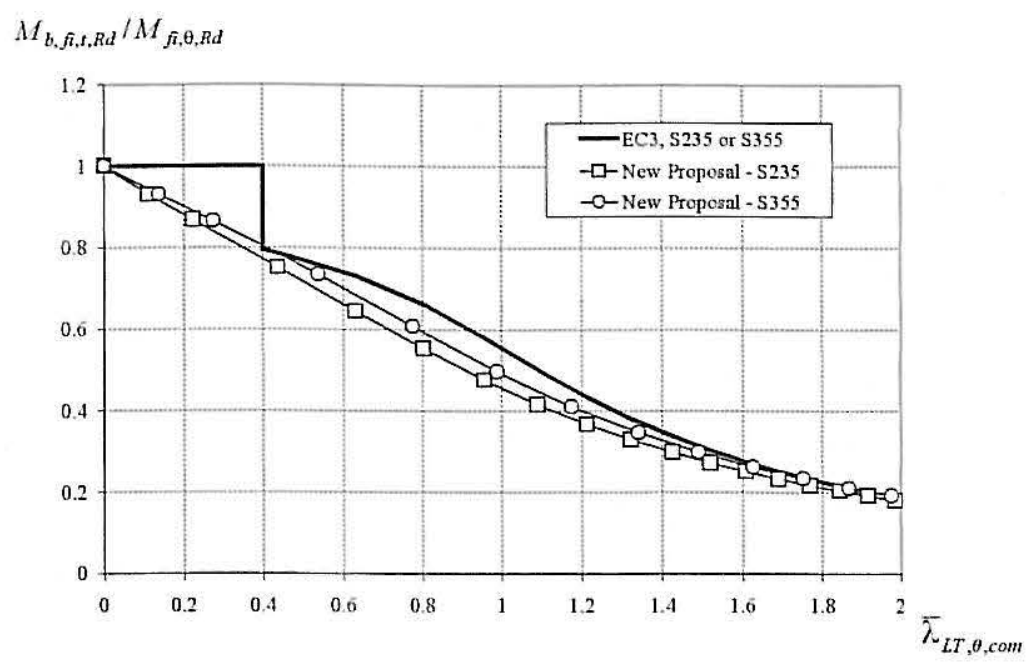

Fig. 5. Comparison between design buckling curve from EC3 and the new proposal. 


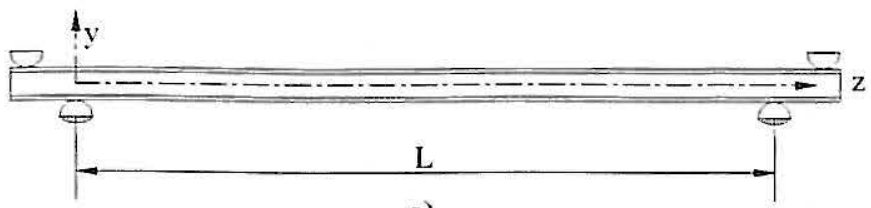

a)

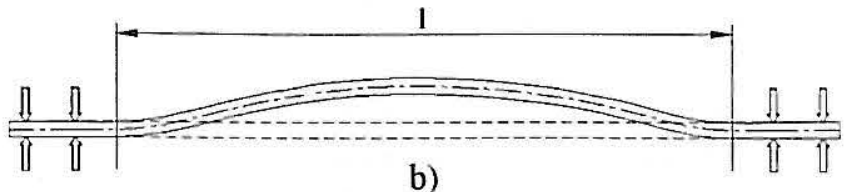

Fig. 6. Effective lateral buckling length, $l=k L$.

a) Elevation; b) Plan 


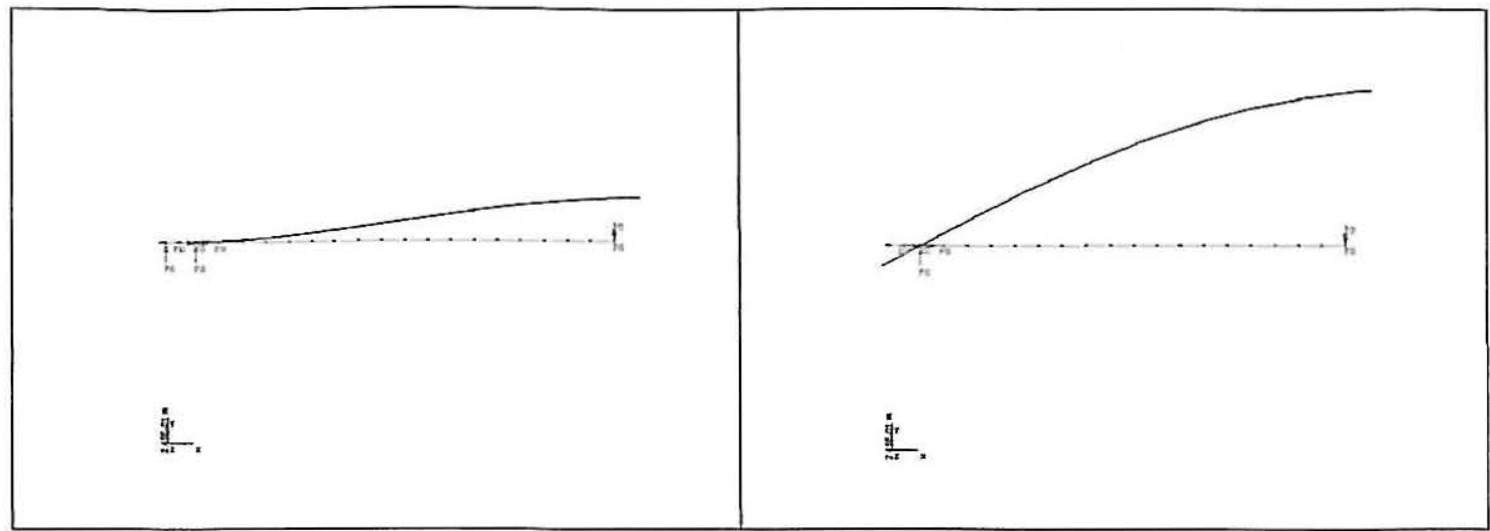

a)

b)

Fig. 7. Plan view from the lateral deformation of the beam at $600{ }^{\circ} \mathrm{C}$ (displacements amplified by a factor 20). a) Restrained lateral movement; b) Unrestrained lateral movement. 


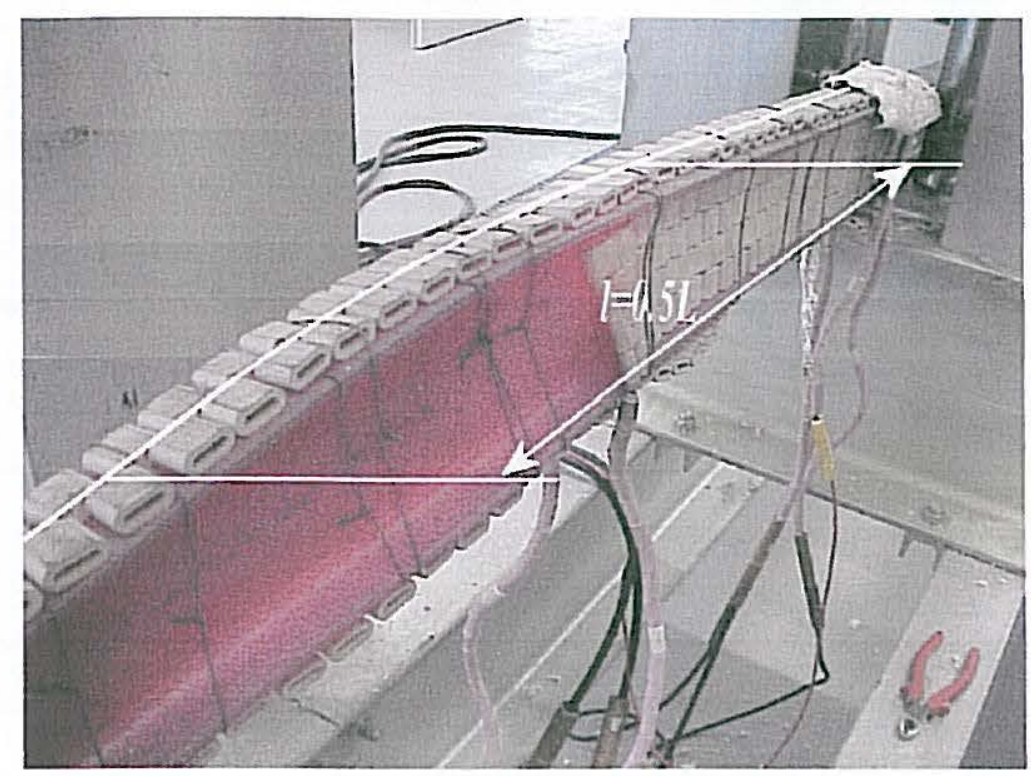

Fig. 8. Deformed beam after heated to $600^{\circ} \mathrm{C}$. Experimental test. 


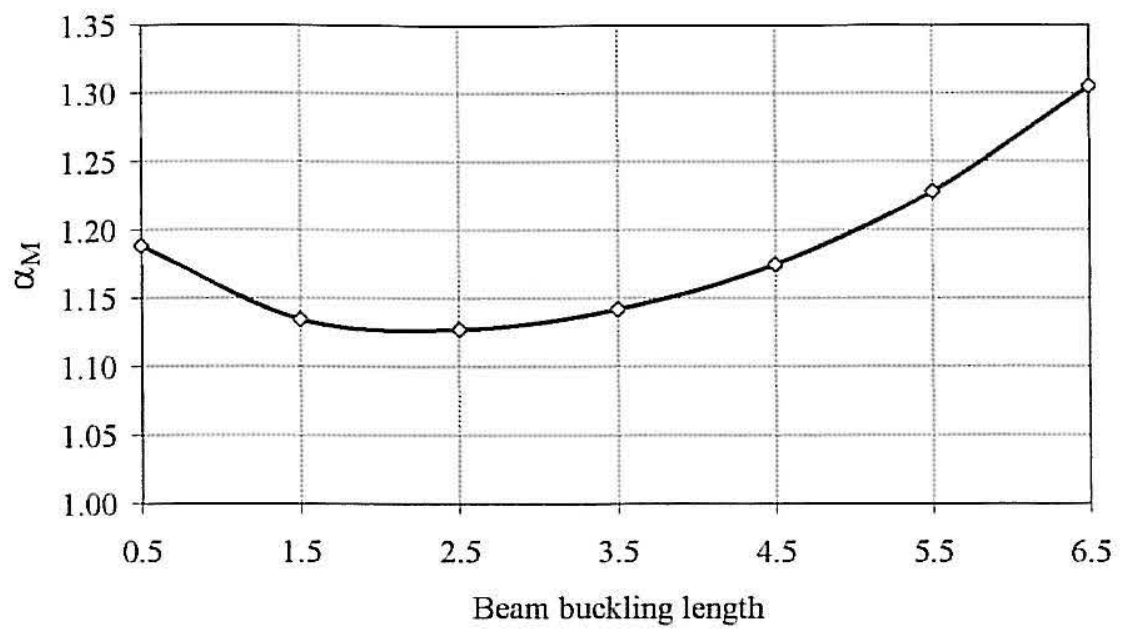

Fig. 9. Moment distribution factor $\alpha_{M}$ (length in meters). 


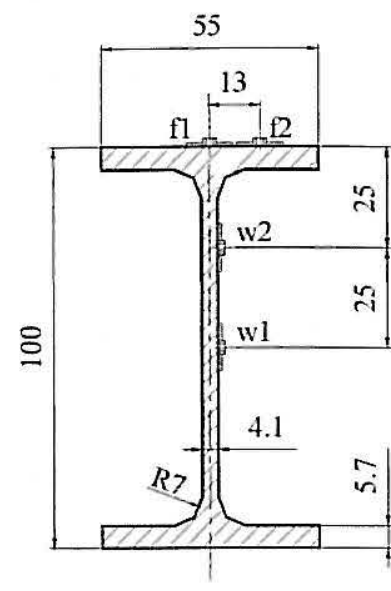

a)

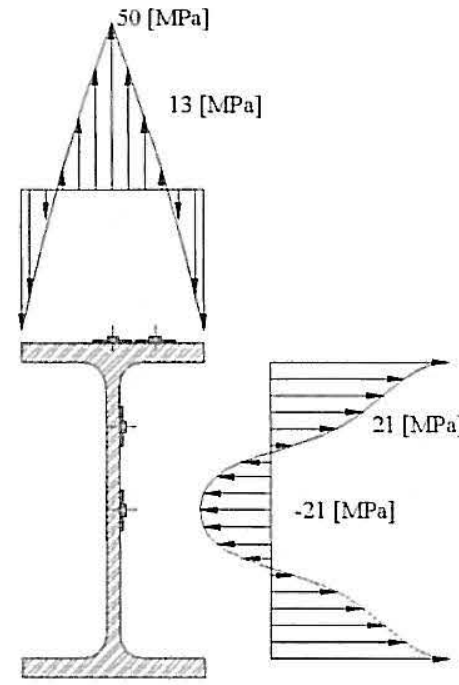

b)

Fig. 10. a) Points of measurement of the residual stresses. b) Assumed distribution of the residual stresses. 


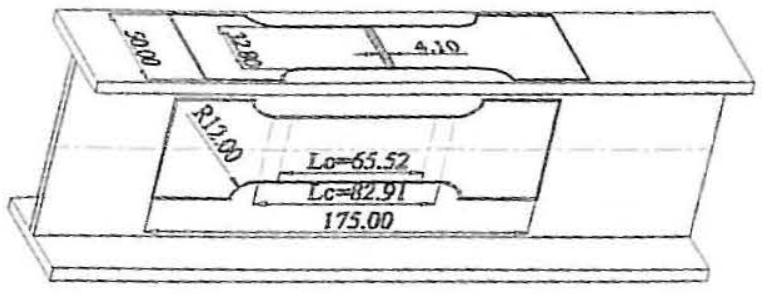

Fig. 11. Tensile specimens. 


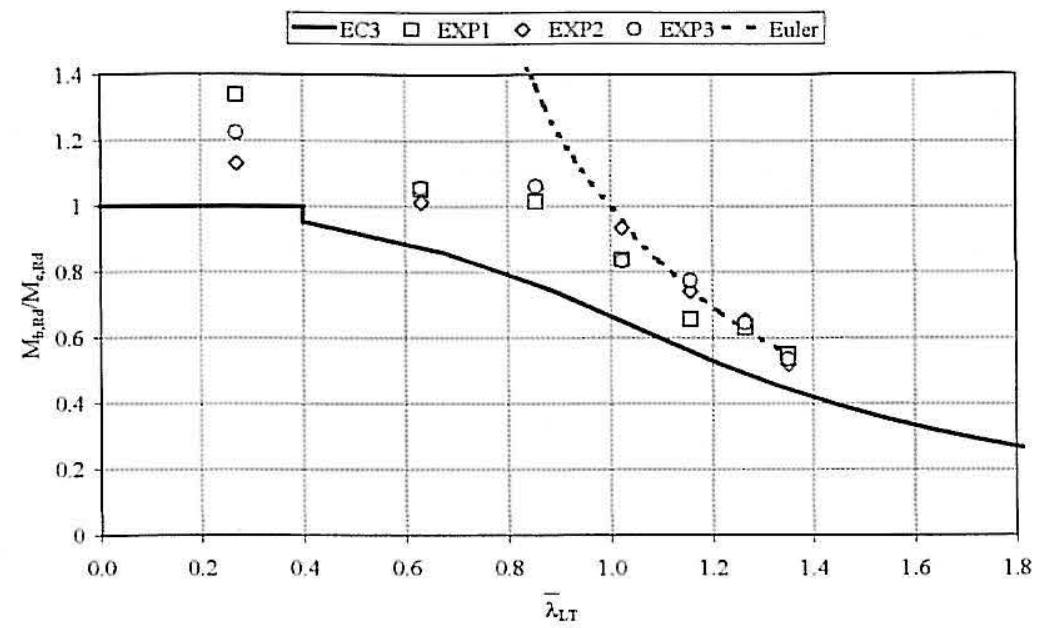

a) Beam at room temperature.

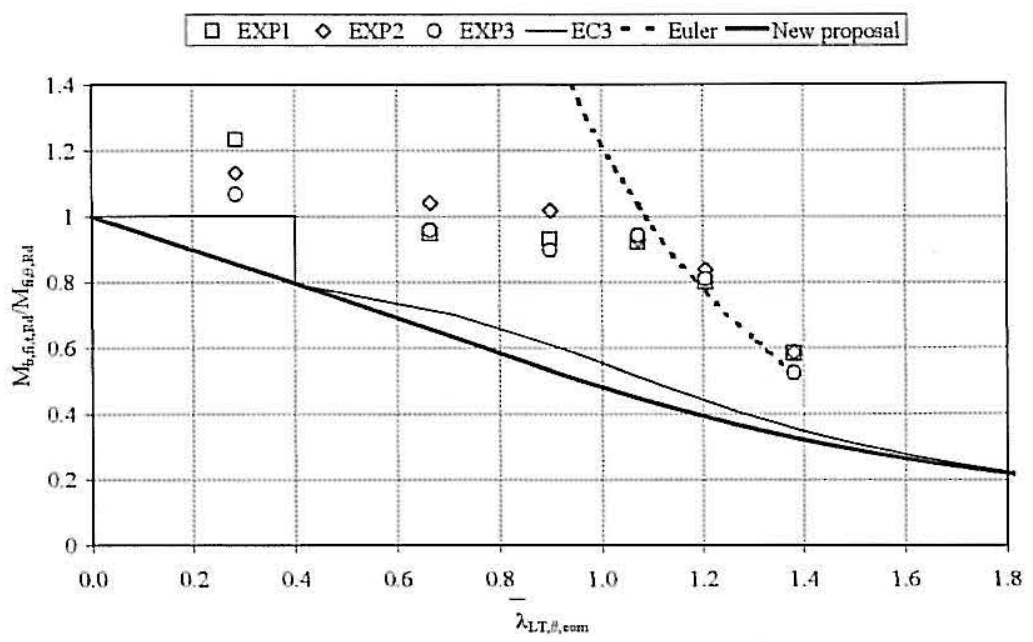

b) Beam at $200{ }^{\circ} \mathrm{C}$.

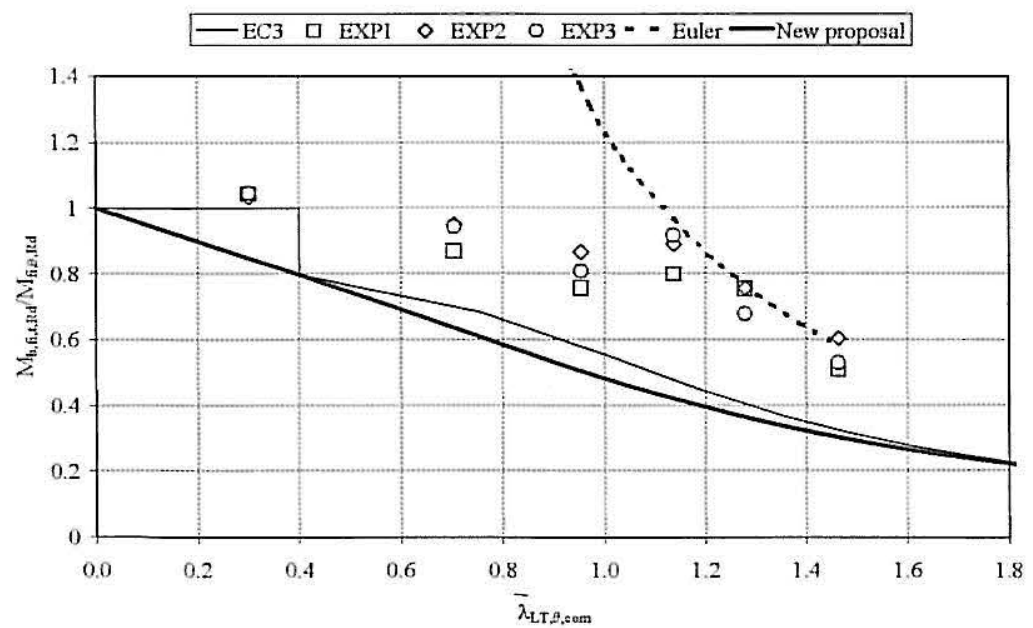

c) Beam at $300^{\circ} \mathrm{C}$. 


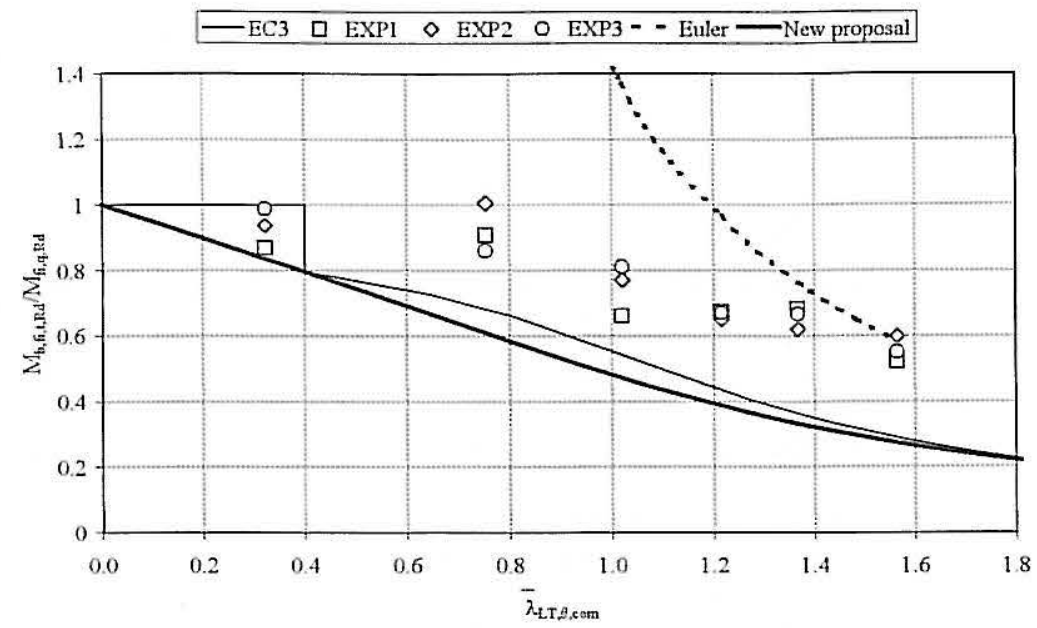

d) Beam at $400{ }^{\circ} \mathrm{C}$.

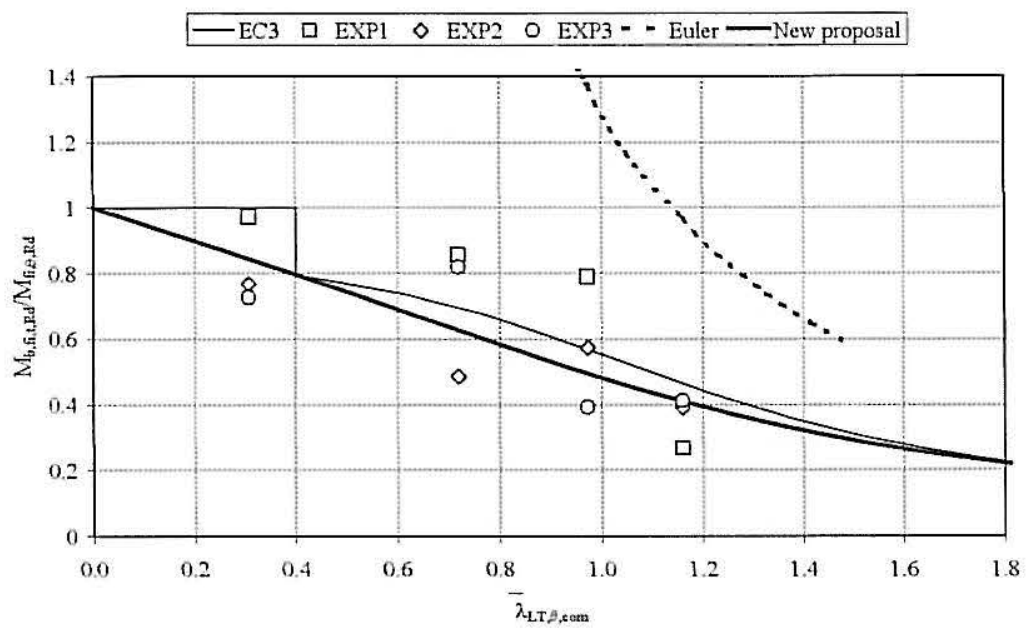

e) Beam at $500{ }^{\circ} \mathrm{C}$.

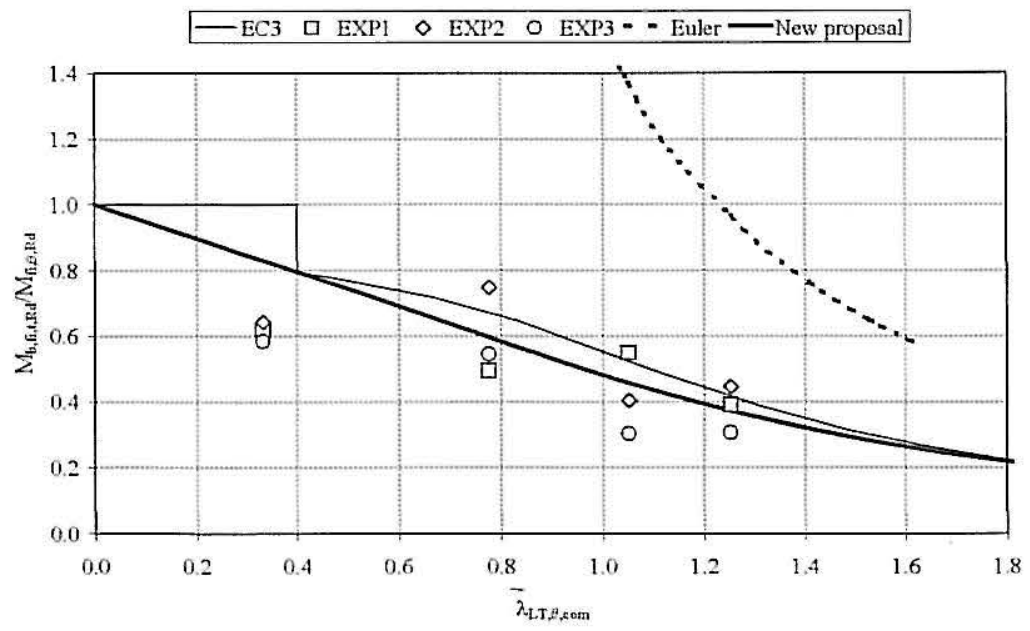

f) Beam at $600{ }^{\circ} \mathrm{C}$.

Fig. 12. Lateral buckling resistance for each tested temperature. Experimental results 


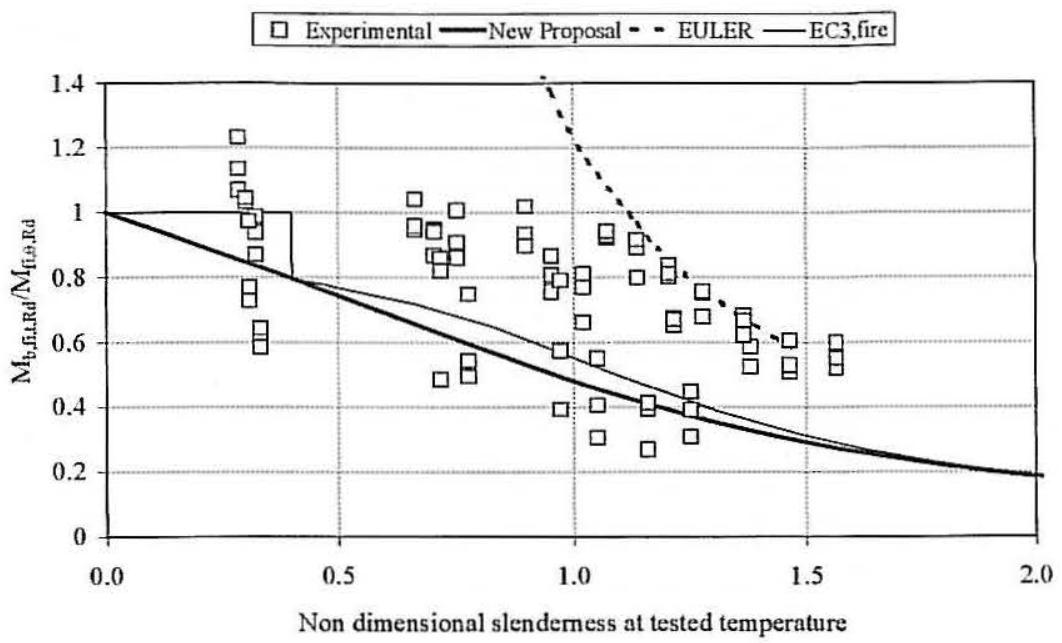

Fig. 13. Beam design curves at elevated temperatures. Experimental results. 


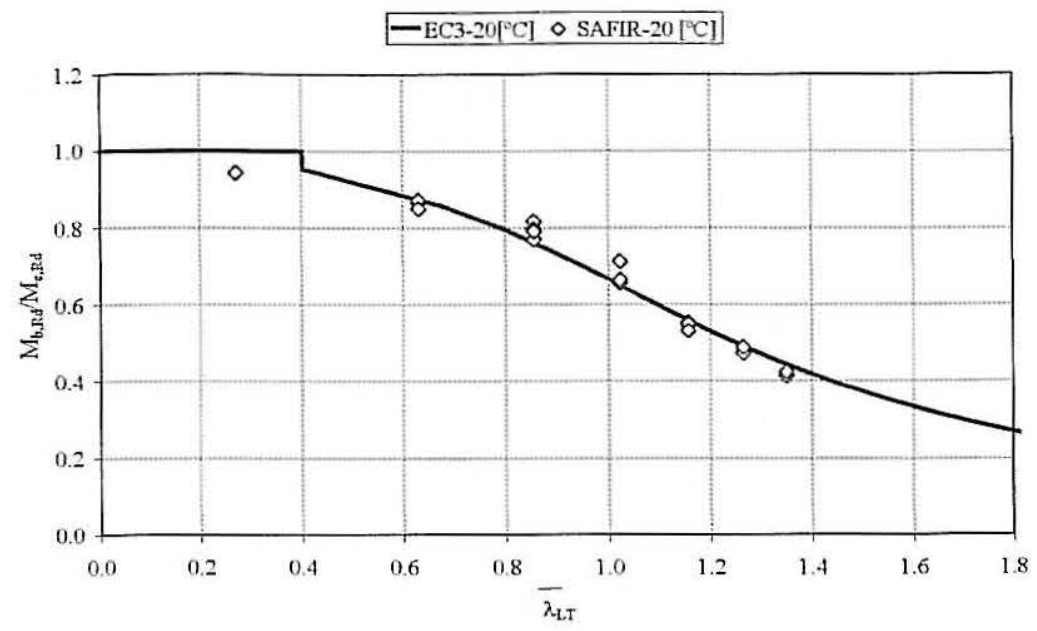

a) Beam at room temperature.

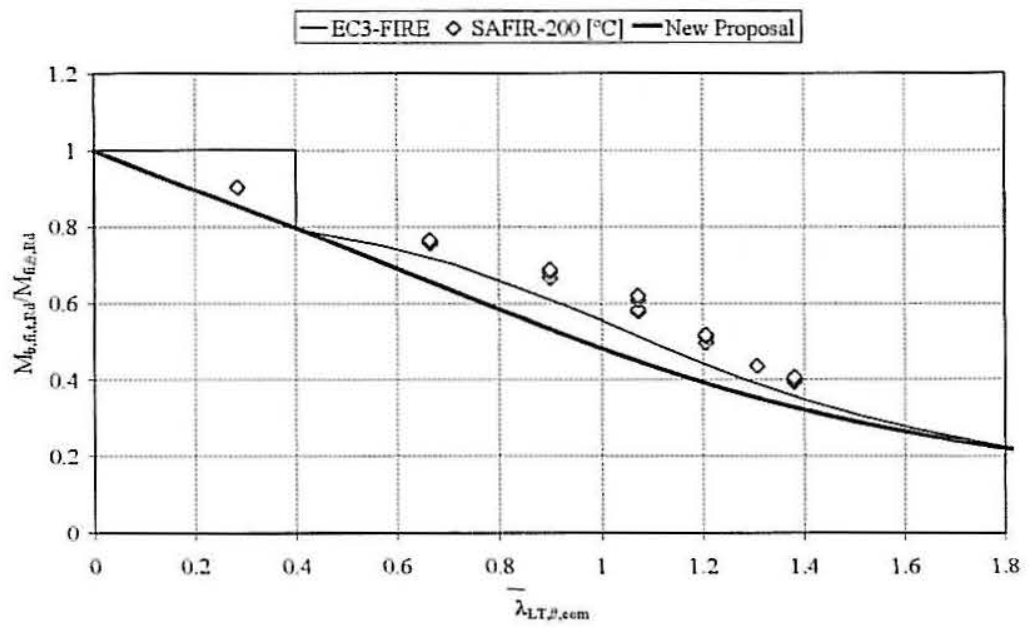

a) Beam at $200{ }^{\circ} \mathrm{C}$.

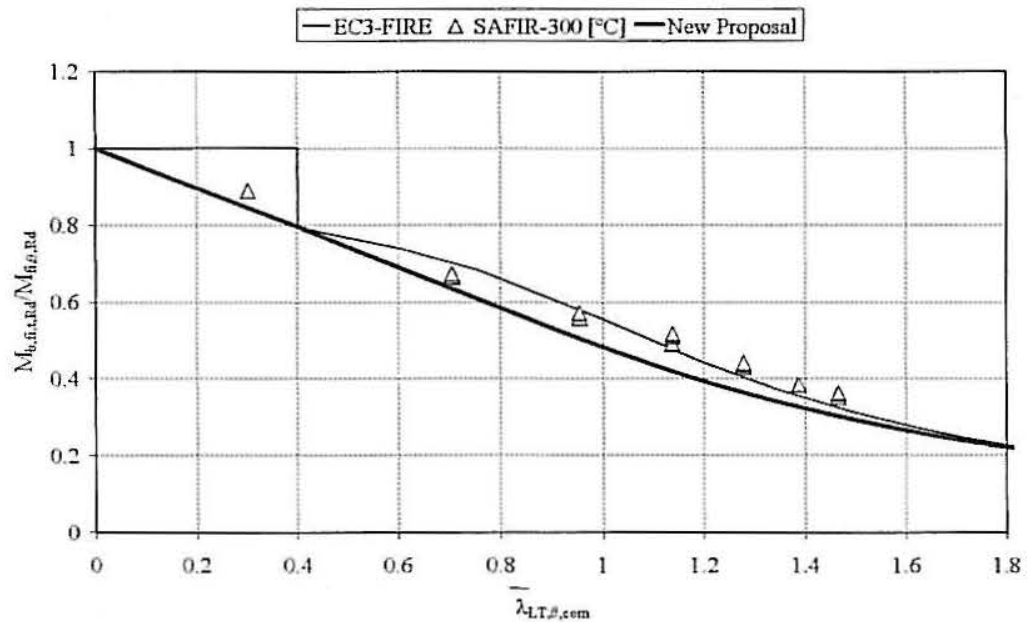

c) Beam at $300^{\circ} \mathrm{C}$. 


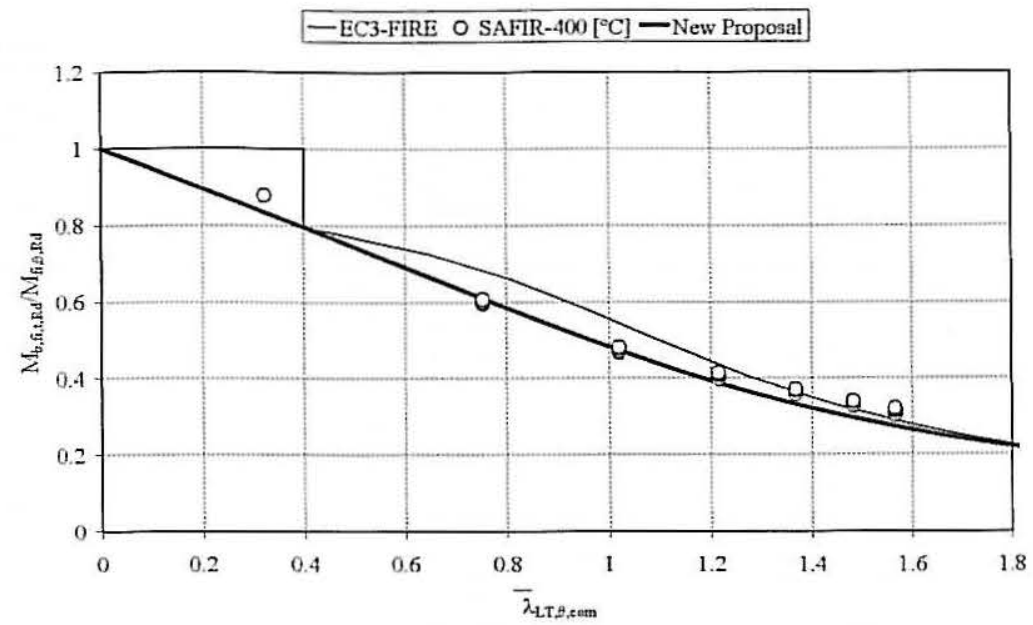

d) Beam at $400^{\circ} \mathrm{C}$.

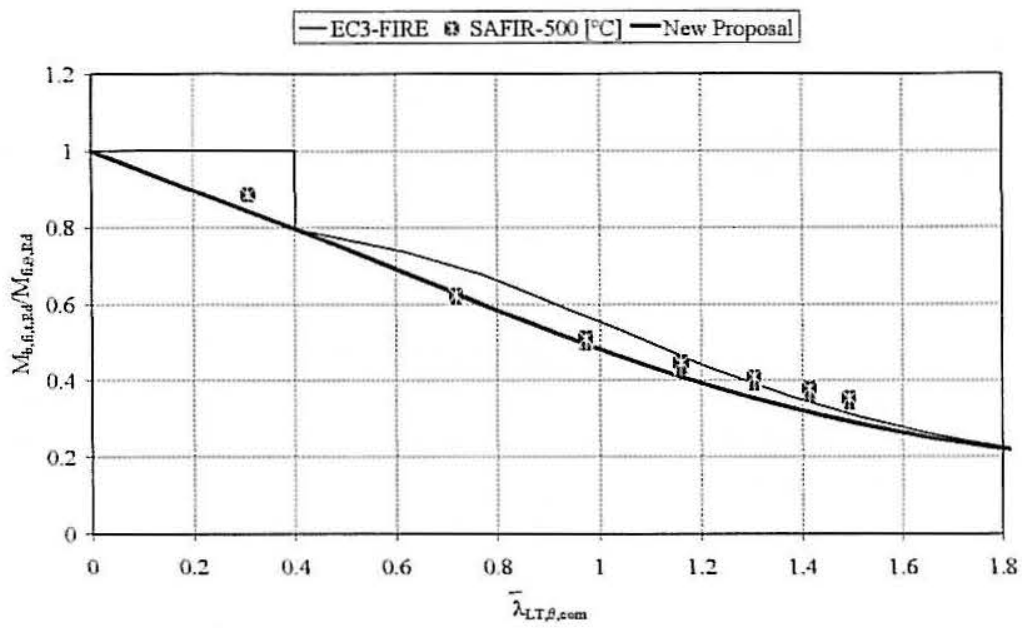

e) Beam at $500{ }^{\circ} \mathrm{C}$.

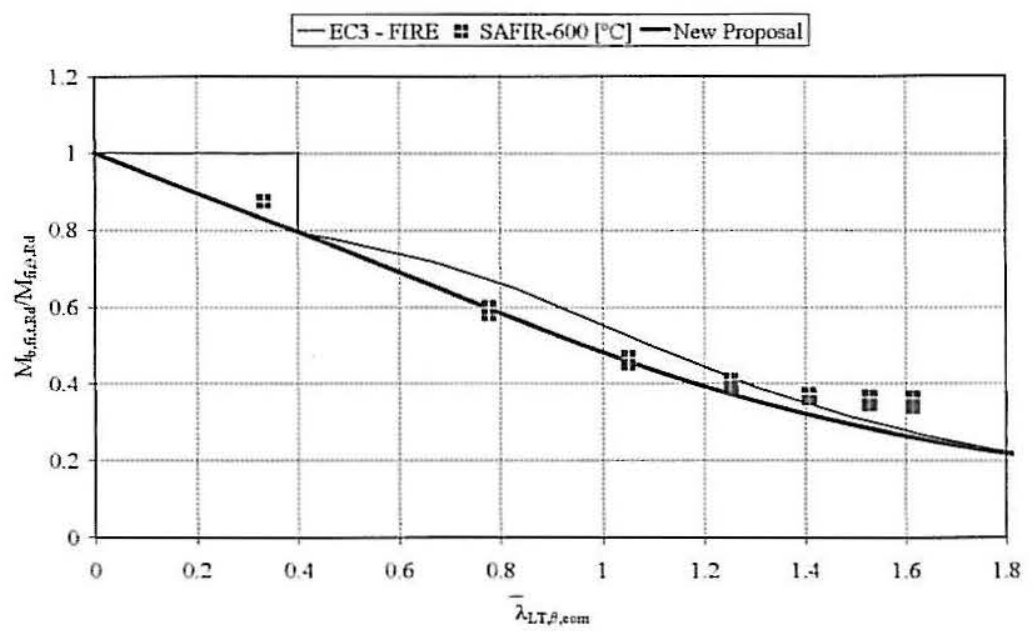

f) Beam at $600{ }^{\circ} \mathrm{C}$.

Fig. 14. Lateral buckling resistance for each tested temperature. Numerical results 


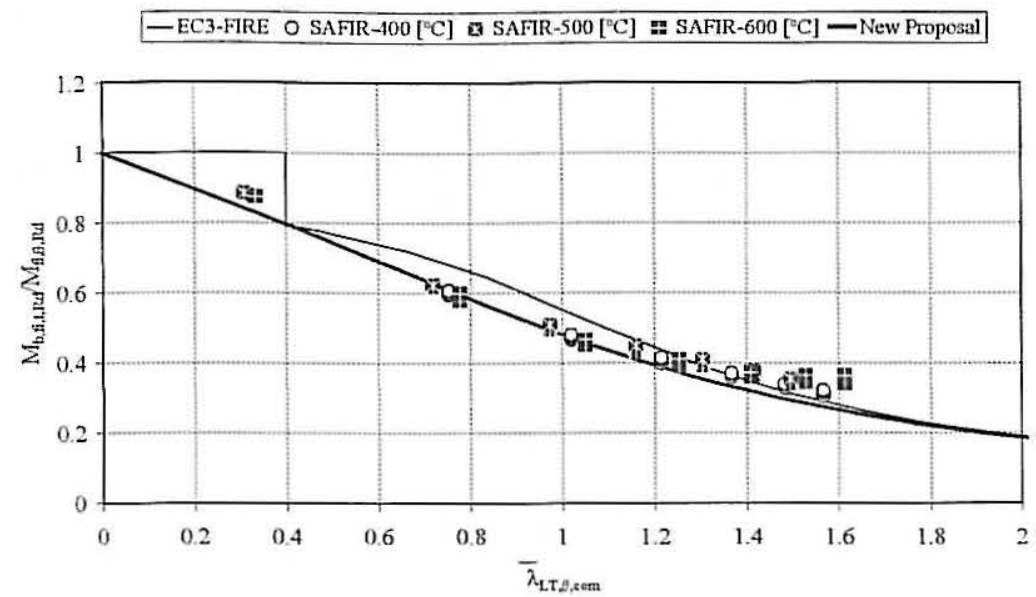

Fig. 15. Beam design curves at elevated temperatures. Numerical results. 


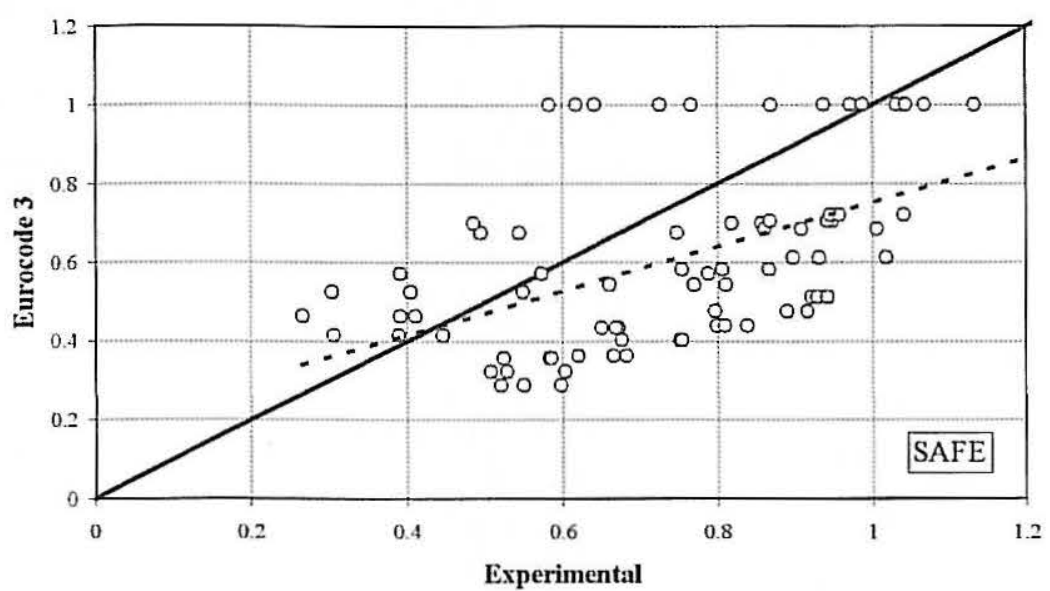

a)

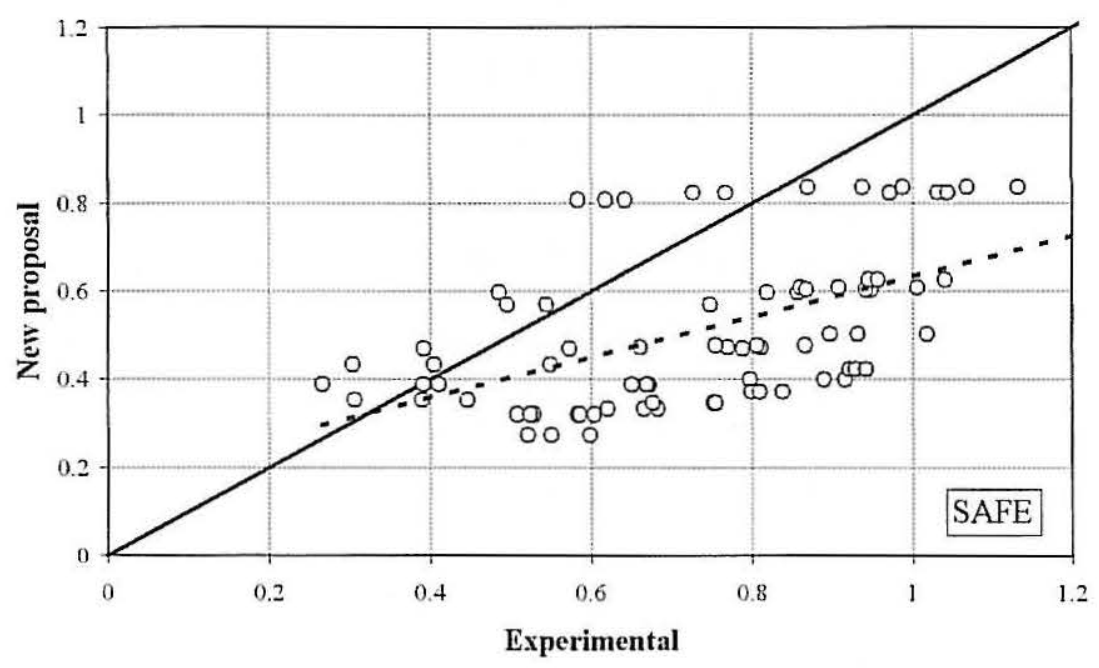

b)

Fig. 16. Experimental behaviour, for elevated temperatures (above $400^{\circ} \mathrm{C}$ ). 


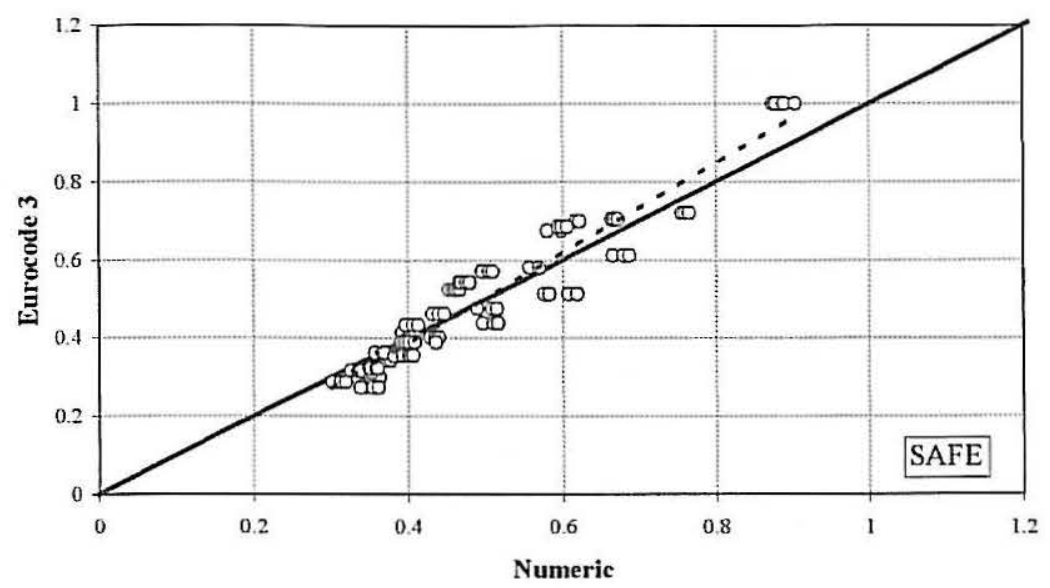

a)

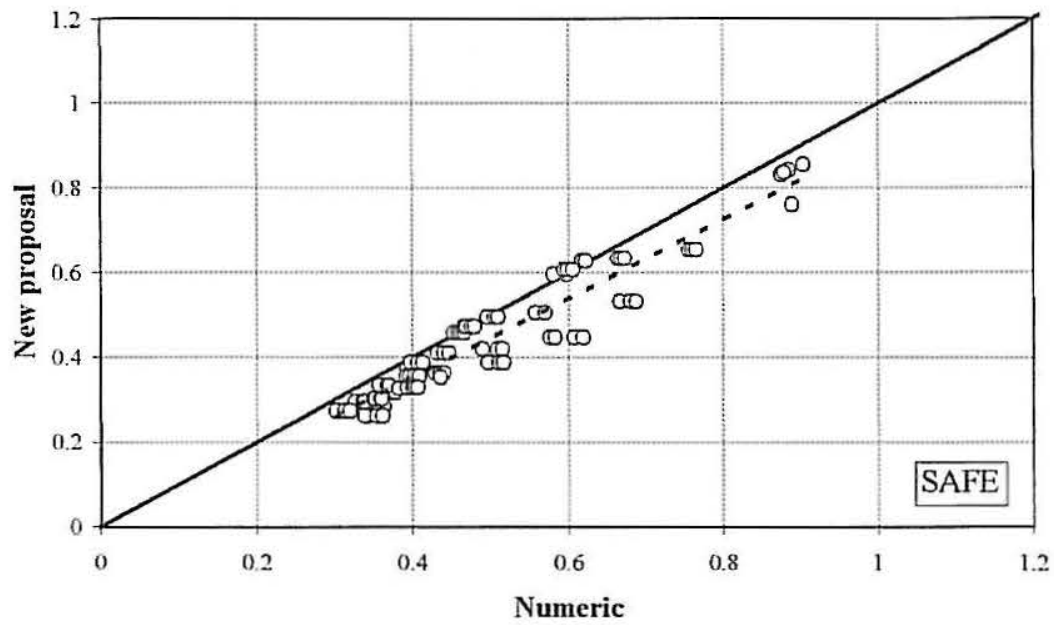

b)

Fig. 17. Numerical behaviour, for elevated temperatures (above $400{ }^{\circ} \mathrm{C}$ ). 
TABLE 1

Experimental results of residual stresses.

\begin{tabular}{ccccc}
\hline Specimen & $\begin{array}{c}\text { Flange (f1) } \\
\text { (Mpa) }\end{array}$ & $\begin{array}{c}\text { Flange (f2) } \\
(\text { Mpa) }\end{array}$ & $\begin{array}{c}\text { Web (w1) } \\
(\text { Mpa) }\end{array}$ & $\begin{array}{c}\text { Web (w2) } \\
\text { (Mpa) }\end{array}$ \\
\hline P31 & NM & 8 & NM & 1 \\
P23 & NM & NM & NM & 20 \\
P34 & 45 & NM & NM & NM \\
P33 & 41 & 15 & NM & 20 \\
P44 & NM & 4 & NM & 38 \\
P40 & 54 & 18 & -22 & 26 \\
P37 & 80 & 6 & -12 & 20 \\
P01 & 35 & NM & -32 & 6 \\
P21 & 46 & 7 & -25 & 34 \\
P11 & 50 & 31 & -12 & NM \\
\hline Average & $\mathbf{5 0}$ & $\mathbf{1 3}$ & $\mathbf{- 2 1}$ & $\mathbf{2 1}$ \\
\hline NM - Not measured value & & &
\end{tabular}

NM - Not measured value 
TABLE 2

Maximum amplitude of the geometric beams imperfection.

\begin{tabular}{|c|c|c|c|c|c|c|c|c|c|c|c|c|c|c|}
\hline 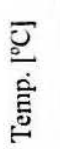 & 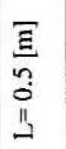 & $=$ & 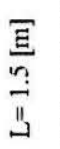 & : & $\begin{array}{l}\text { 豆 } \\
\text { in } \\
\text { in } \\
\text { "I }\end{array}$ & \& & 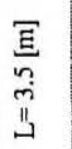 & $=$ & 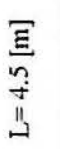 & $=$ & 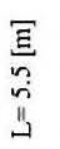 & $\Rightarrow$ & 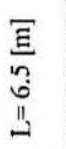 & $\Rightarrow$ \\
\hline 20 & P31 & 0.5 & P33 & 1.0 & P36 & 1.5 & $\mathrm{P} 01$ & 3.0 & P20 & 7.0 & P22 & 3.0 & P11 & 7.0 \\
\hline 20 & P31 & 0.5 & P33 & 1.0 & P35 & 1.5 & P02 & 1.0 & P17 & 5.0 & P23 & 3.0 & P17 & 7.0 \\
\hline 20 & P31 & 0.5 & P33 & 3.0 & P36 & 0.5 & P07 & 3.0 & $\mathrm{P} 20$ & 5.0 & P27 & 3.0 & P12 & 4.0 \\
\hline 200 & P31 & 0.5 & P33 & 0.5 & P38 & 1.0 & P38 & 1.5 & P23 & 2.5 & - & $\mathrm{NM}$ & P19 & 3.0 \\
\hline 200 & P31 & 0.5 & P34 & 1.0 & P41 & 1.5 & P38 & 3.0 & P21 & 3.0 & - & NM & P20 & 4.5 \\
\hline 200 & P04 & 0.5 & P33 & 0.5 & P39 & 1.5 & P39 & 1.0 & P30 & 2.5 & - & $\mathrm{NM}$ & P14 & 4.0 \\
\hline 300 & P05 & 0.5 & P33 & 0.5 & P38 & 1.0 & P41 & 3.5 & $\mathrm{P} 28$ & 3.0 & - & $\mathrm{NM}$ & P15 & 3.5 \\
\hline 300 & P02 & 0.5 & P34 & 0.5 & P37 & 1.0 & P39 & 1.5 & P24 & 3.5 & - & NM & P16 & 4.0 \\
\hline 300 & P31 & 0.5 & P34 & 1.0 & P36 & 1.0 & P40 & 1.0 & P25 & 3.0 & - & NM & P13 & 6.0 \\
\hline 400 & P07 & 0.5 & P20 & 1.5 & P40 & 0.5 & P40 & 1.0 & P15 & 2.5 & P25 & 2.5 & P18 & 7.5 \\
\hline 400 & P06 & 0.5 & P09 & 1.0 & P46 & 1.0 & P37 & 2.0 & P25 & 2.5 & P08 & 3.0 & P10 & 2.0 \\
\hline 400 & P31 & 0.5 & P08 & 0.5 & P44 & 2.0 & P41 & 4.0 & P26 & 2.0 & P09 & 2.5 & P02 & 3.5 \\
\hline 500 & P31 & 0.5 & P43 & 1.0 & P43 & 1.0 & P06 & 1.0 & P16 & 1.5 & P29 & 3.0 & P05 & 3.0 \\
\hline 500 & P31 & 0.5 & P42 & 1.0 & $\mathrm{P} 42$ & 1.0 & P04 & 1.0 & P14 & 2.5 & P27 & 2.0 & P07 & 6.0 \\
\hline 500 & P10 & 0.5 & P44 & 1.0 & P45 & 0.5 & P05 & 2.0 & P18 & 3.5 & P26 & 2.0 & P06 & 4.5 \\
\hline 600 & $\mathrm{P} 03$ & 0.5 & P46 & 1.5 & P42 & 1.5 & P10 & 0.5 & P13 & 4.0 & P28 & 4.0 & P01 & 8.0 \\
\hline 600 & P01 & 0.5 & P45 & 0.5 & P43 & 0.5 & P09 & 1.5 & P12 & 3.0 & P30 & 1.0 & $\mathrm{P} 03$ & 6.0 \\
\hline 600 & P31 & 0.5 & P43 & 1.5 & P46 & 1.0 & $\mathrm{P} 03$ & 1.0 & $P$ & 2.0 & P22 & 2.0 & P04 & 2.0 \\
\hline
\end{tabular}


TABLE 3

Cross section dimensions.

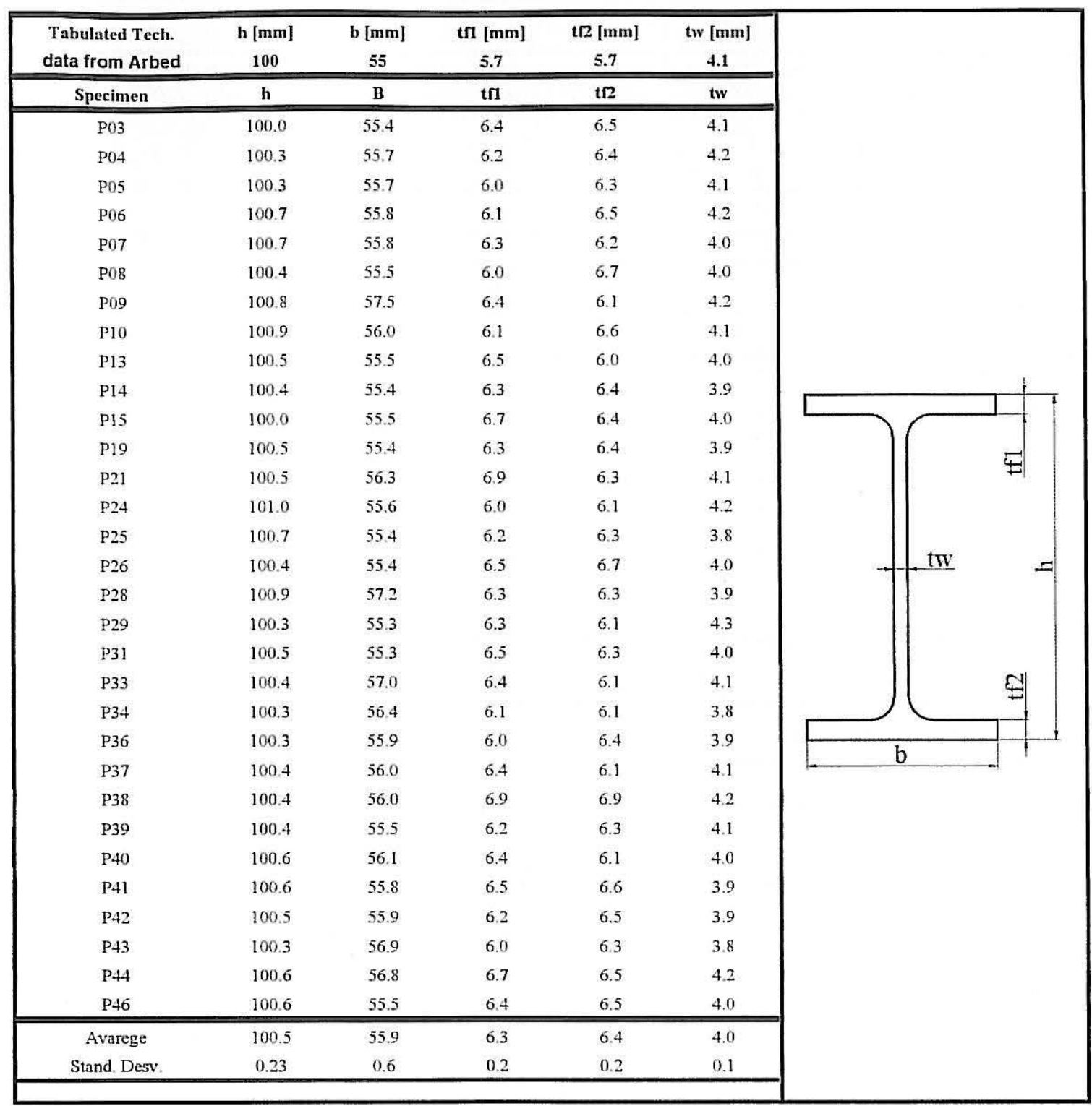


TABLE 4

Material strength characterisation.

\begin{tabular}{cccccc}
\hline Beam & Location & $\begin{array}{c}\text { Maximum } \\
\text { load } \\
\text { [kN] }\end{array}$ & $\begin{array}{c}\text { Stress at } \\
\text { maximum load } \\
\text { [MPa] }\end{array}$ & $\begin{array}{c}\text { Elasticity } \\
\text { Modulus } \\
\text { [MPa] }\end{array}$ & $\begin{array}{c}\text { Yield } \\
\text { Strength } \\
\text { [MPa] }\end{array}$ \\
\hline P31 & web & 55.410 & 412.031 & 209447 & 305.024 \\
P31 & web & 54.090 & 402.216 & 202930 & 297.837 \\
P31 & web & 54.630 & 406.231 & 324456 & 302.828 \\
P31 & web & 55.650 & 413.816 & 156675 & 322.790 \\
P20 & web & 56.910 & 432.447 & 257548 & 321.287 \\
P24 & web & 57.720 & 435.952 & 220890 & 334.552 \\
P30 & web & 58.820 & 445.606 & 232605 & 345.125 \\
P30 & web & 58.010 & 440.805 & 182795 & 338.218 \\
P25 & web & 57.610 & 440.443 & 294006 & 330.025 \\
P21 & web & 57.660 & 443.538 & 166271 & 345.065 \\
P26 & web & 56.750 & 419.438 & 262188 & 316.866 \\
P31 & flange & 57.150 & 424.970 & 146026 & 325.984 \\
P31 & flange & 54.090 & 402.216 & 202930 & 297.837 \\
P31 & flange & 69.800 & 452.772 & 186776 & 315.000 \\
P31 & flange & 60.480 & 449.732 & 229050 & 311.811 \\
P31 & flange & 62.070 & 450.566 & 262974 & 312.377 \\
P31 & flange & 63.170 & 453.026 & 217057 & 316.210 \\
P31 & flange & NM & NM & 249754 & 315.000 \\
P31 & flange & NM & NM & 146223 & 325.000 \\
P31 & flange & 63.543 & 453.294 & 265968 & 320.000 \\
\hline Average & & 58.531 & 432.172 & 220828 & 320.000 \\
S.D. & & 4.007 & 18.540 & 49019 & 14.000 \\
\hline
\end{tabular}

